Portland State University

PDXScholar

1983

\title{
Level of aspiration and the Type A coronary-prone pattern in children
}

Wendy L. Kliewer

Portland State University

Follow this and additional works at: https://pdxscholar.library.pdx.edu/open_access_etds

Part of the Applied Behavior Analysis Commons, and the Personality and Social Contexts Commons Let us know how access to this document benefits you.

Recommended Citation

Kliewer, Wendy L., "Level of aspiration and the Type A coronary-prone pattern in children" (1983).

Dissertations and Theses. Paper 3270.

https://doi.org/10.15760/etd.3260

This Thesis is brought to you for free and open access. It has been accepted for inclusion in Dissertations and Theses by an authorized administrator of PDXScholar. Please contact us if we can make this document more accessible: pdxscholar@pdx.edu. 


\section{AN ABSTRACT OF THE THESIS OF Wendy L. Kliewer for the Master of Science in Psychology presented August 15, 1983.}

Title: Level of Aspiration and the Type A Coronary-Prone Behavior Pattern in Children.

APPROVED BY MEMBERS OF THE THESIS COMMITTEE:

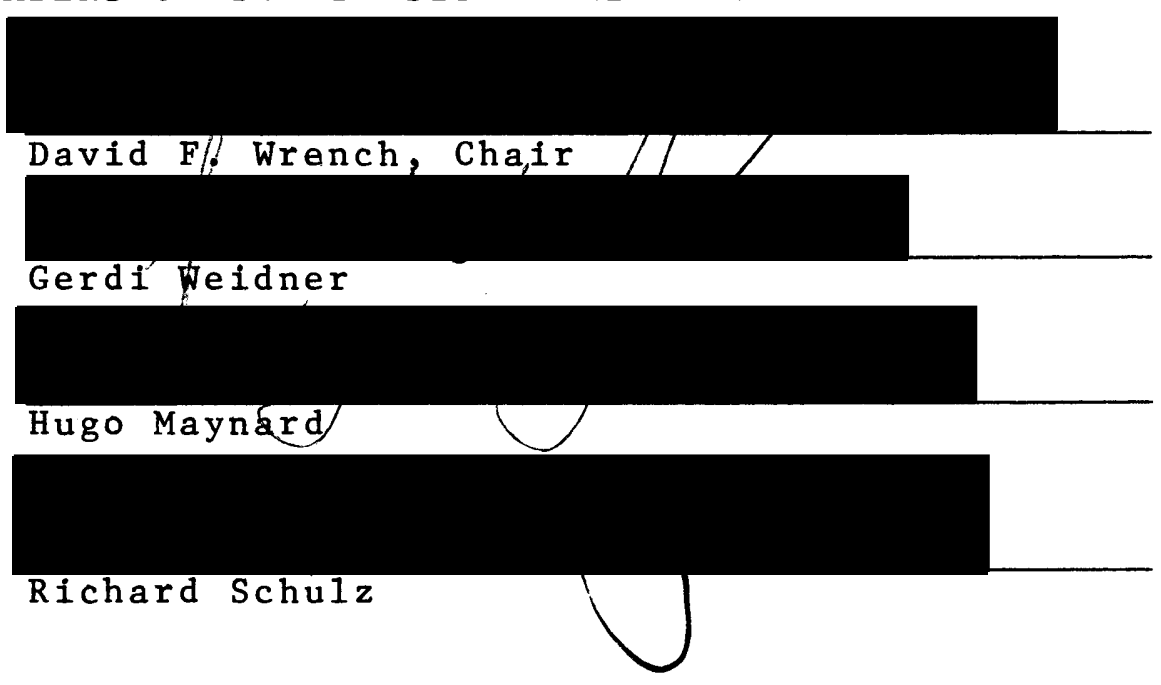

Type A coronary-prone behavior has been recognized as a major risk factor for coronary heart disease. Characterized by extremes of achievement-striving, impatienceaggression, and easily aroused hostility, this behavior pattern has been studied extensively in adults, but relatively few studies have examined the behavior pattern in children.

The purpose of the present investigation was to examine aspects of assessment of the Type A behavior pattern, goal-setting behaviors displayed by Type $A$ and $B$ children, and parents' goal-setting behaviors toward their offspring.

Type A behavior in children is most frequently assessed by two instruments, the Matthews Youth Test for 
Health (MYTH) and the Hunter-Wolf A-B Rating Scale. Because research on Type A behavior in children is relatively new, few comparisons between measures have been made. Both instruments were administered in the present study in order to determine the relationship between them. Results indicated that the instruments correlated only margina $11 \mathrm{y}$.

Second, goal-setting behavior was assessed in 30 male and 34 female Type $A$ and $B$ 9- to 12-year-olds. Past research with Type A and $B$ men (Snow, 1978) indicated that Type A men set higher goals for themselves than Type B men. The present investigation explored goalsetting in children using Snow's (1978) procedure. Finally, in order to determine parental influences on the development of Type A behavior, questionnaires were administered to 37 mothers and 27 fathers assessing expectations and goal-setting behaviors toward their children,

Results indicated that Type A children (as assessed by the MYTH) did not set higher goals for themselves than did Type B children. Type A females did, however, perform at significantly higher levels than Type B females. The hypothesis that parents of Type As set higher goals for their children than parents of Type Bs was partially supported in daughters only. Mothers perceived their goals to be higher for daughters scoring high on Type A characteristics. They also indicated that the more Type A behavior their daughters displayed, the less likely their daughters were to attain these goals. Fathers indicated that the greater the degree of Type A behavior in their daughters, the more likely they were to have high educational aspirations for them. Additionally, fathers reported that daughers with high Type A scores are aware of what is expected of them. 
These findings suggest that although 9- to 12-year old Type As did not differ from Bs in their goal-setting behavior in the present study, parental goal-setting tends to be higher for female Type A children than for female Type B children. 
LEVEL OF ASPIRATION AND THE TYPE A CORONARY-PRONE BEHAVIOR PATTERN IN CHILDREN

by

WENDY L. KLIEWER

A thesis submitted in partial fulfillment of the requirements for the degree of

\author{
MASTER OF SCIENCE \\ in \\ PSYCHOLOGY
}

Portland State University

1983 
TO THE OFFICE OF GRADUATE STUDIES AND RESEARCH:

The members of the Committee approve the thesis of Wendy L. Kliewer presented August 15, 1983.

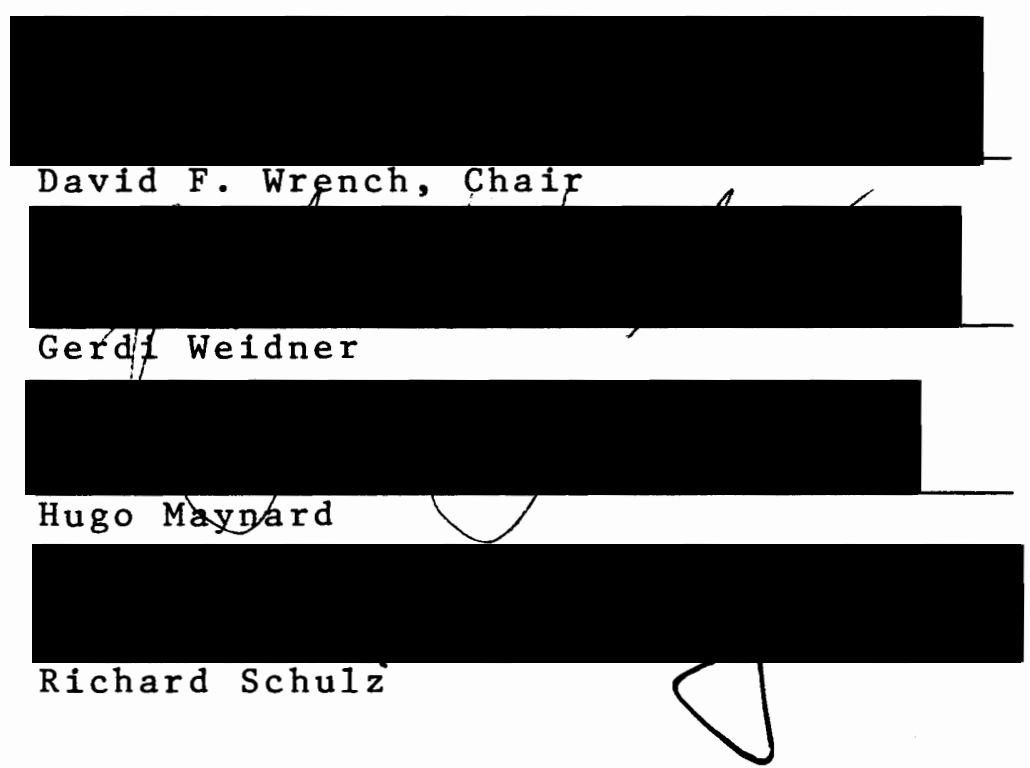

APPROVED :

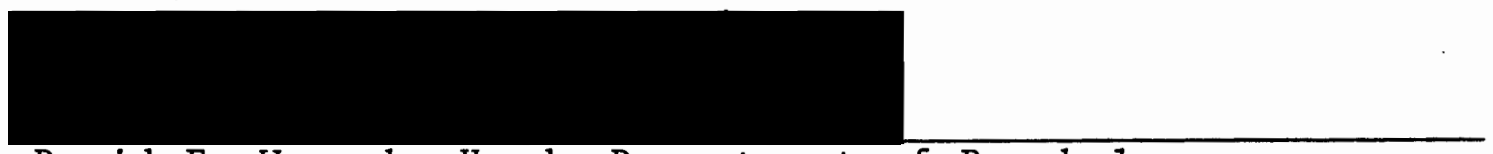

David F. Wrench, Head, Department of Psychology

Stanley-E. Rauch, Dean of Graduate Studies and Research 


\section{ACKNOWLEDGEMENTS}

I wish to express my appreciation and gratitude to Mrs. Jane DeMarco, Past-Principal of Cathedral School, for her support of my research, and the fourth, fifth, and sixth grade students of Cathedral and their parents for participating in this study.

I also wish to thank the members of my thesis committee for their support throughout this project. I am particularly grateful to Dr. Gerdi Weidner, who supervised my work. Your time, patience, and instruction, Dr. Weidner, have been an invaluable part of this project. I thank you. 
TABLE OF CONTENTS

PAGE

ACKNOWLEDGEMENTS....................... ii

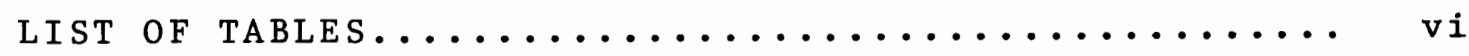

CHAPTER

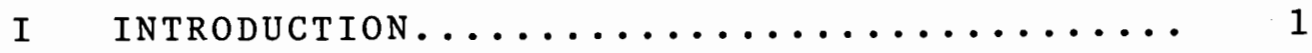

Research on Children................ 4

Assessment of Type A Behavior in

Children....................... 4

Physiological Characteristics of

Type A Children................. 5

Psychological Characteristics of

Type A Children................

Construct Validation

Type A and Goal-setting Behavior Parental Correlates of Type A

Behavior in Children

II $\quad$ METHOD ......................... 12

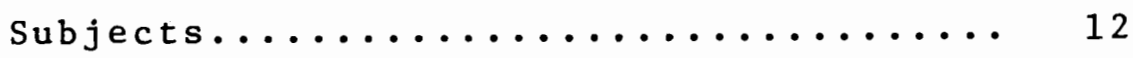

Assessment of Type A Behavior.......... 12

Assessment of Parenta1 Aspirations..... 13

Assessment of Children's Aspirations.... 14

Dependent Measures................ 14

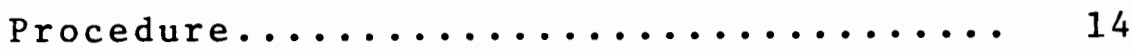

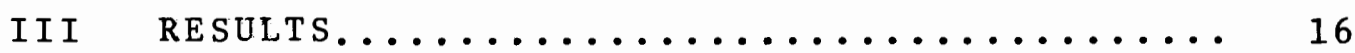

Correlations Between Assessment

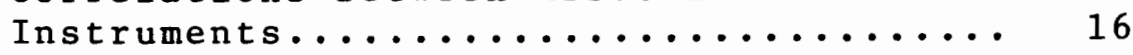

Children's Aspirations and Performance.. 21

Parenta1 Aspirations................. 24 
Children's Aspirations and Performance.. 32

Parental Aspirations.............. 33

Measurement of the Type A Behavior

Pattern........................... 35

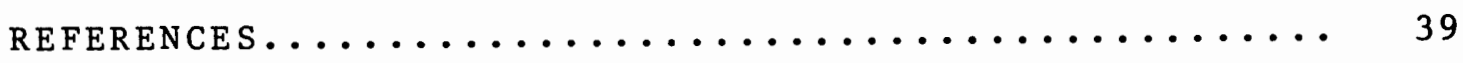

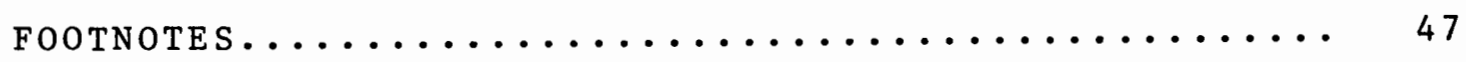

APPENDICIES

A Informed Consents............... 49

B Measures Used to Assess Type A Behavior.. 55

C Measures Used to Assess Aspirations..... 63

D Experimental Instructions........... 73 


\section{LIST OF TABLES}

TABLE

PAGE

I Medians, Means, and Standard Deviations of

the Matthews Youth Test for Health for

Boys and $\operatorname{Gir} 1 s \ldots \ldots \ldots \ldots \ldots \ldots \ldots$

I Medians, Means, and Standard Deviations of

the Hunter-Wolf A-B Rating Scale for

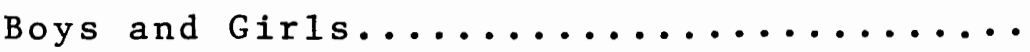

II Correlations Between the Matthews Youth Test

for Health, the Hunter-Wolf A-B Rating

Scale, and Their Factors for Boys.......

IV Correlations Between the Matthews Youth Test

for Health, the Hunter-Wolf A-B Rating

Scale, and Their Factors for Girls......

$V$ Level of Aspiration for Male Type $A$ and $B$

Children on Puzzles 1 - 5...........

VI Level of Aspiration for Female Type $A$ and

B Children on Puzzles 1 - 5...........

VII Puzzle Performance for Male Type $A$ and $B$

Children on Puzzles 1 - 5............

VIII Puzzle Performance for Female Type A and

B Children on Puzzles 1 1 ...........

IX Correlations Between the Matthews Youth

Test for Health and Mothers' and

Fathers' Responses on the Parental

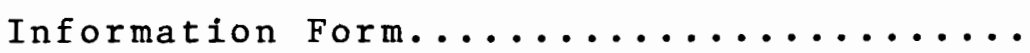

$X$ Mothers' Aspirations as Predictors of Type

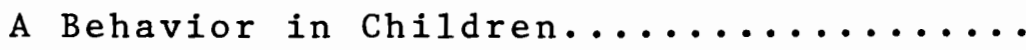

XI Fathers' Aspirations as Predictors of Type

A Behavior in Children.............. 
CHAPTER I

\section{INTRODUCTION}

The Type A coronary-prone behavior pattern has been described by Friedman and Rosenman (1974) as an

action-emotion complex that can be observed in any person who is aggressively involved in a chronic, incessant struggle to achieve more and more in less and less time, and if required to do so, against the opposing efforts of other things and other persons (p. 84)

Thus, the behavior of Type A individuals may best be summarized by three major components: aggressiveness, a sense of time urgency, and impatience-hostility (Rosenman, 1978). The Type A behavior pattern is not considered to be a trait nor a discrete typology. It is, instead, "a set of overt behaviors that is elicited from susceptible individuals by an appropriately challenging environment" (Matthews, 1982, p. 293). Type B persons, by contrast, are individuals who do not display the above characteristics. They are more relaxed and easygoing than Type As.

Two major instruments for assessing the degree of Type A behavior in adults are the structured Interview (SI) (Rosenman et al., 1964) and the Jenkins Activity Survey for Health Prediction (JAS) (Jenkins, Rosenman, \& Friedman, 1967). The Structured Interview is a standardized interview technique in which subjects are asked 26 questions dealing with the intensity of their ambitions, competitiveness, sense of time urgency, and the nature and magnitude of their hostile feelings. Both verbal and nonverbal behaviors are incorporated in scoring the interview. The Jenkins Activity survey is a 52-item self-report questionnaire which also assesses 
competitive drive and time urgency. The adult version of the JAS assesses job involvement as we11. Interrater and test-retest reliability (based on 12 - 20 month separation intervals) for the $\mathrm{SI}$ is .84 and .80 , respectively (Jenkins, Rosenman, \& Friedman, 1968). The test-retest reliability of the adult version of the JAS (based on a 1-year separation interva1) is .66 (Jenkins, Zyzanski, \& Rosenman, 1971).

Both retrospective and prospective studies (e.g., Jenkins, 1976; Jenkins, Rosenman, \& Zyzanski, 1974; Rosenman et al., 1975) have linked Type A behavior with approximately twice the risk of coronary heart disease in both men and women, and degree of atherosclerosis in men (Blumenthal, Williams, Kong, Schanberg, \& Thompson, 1978). However, while Type A behavior has now been firmly established as an independent risk factor for coronary heart disease ( $C H D)$, the pathophysiological mechanisms linking Pattern $A$ and CHD are unclear. Type As, for example, do not differ from Type Bs on other risk factors for CHD (e.g., elevated serum cholesterol, elevated blood pressure) which are measured during resting conditions (see Loval1o \& Pishkin, 1980; Scherwitz, Berton, \& Leventhal. 1978, for examples). Recall that Type A behavior only occurs in an appropriately challenging environment. Therefore, it may not be surprising that physiological measures of Type As taken under resting conditions do not differ from Type Bs. In recent studies examining physiological responses of Type As and Bs to environmental stressors, Type As seem to show a distinct pattern of response. For example, Type A males exhibit higher elevations in systolic blood pressure relative to a resting baseline than Type $B$ males (Contrada et al., 1982; Dembroski, MacDouga11, Herd, \& Shields, 1979 ; Dembroski, MacDouga11, \& Lushene, 1979 ; Dembroski, MacDouga11, Shields, Petito, \& Lushene, 1978 ; Glass et al., 1980; Krantz et al., 1981; Manuck, Craft, \& Gold, 1978; Manuck \& Garland, 1979). Additionally, 
Type A males (relative to Type B males) respond with elevations in plasma epinephrine or norepinephrine (Contrada et a1., 1982; Glass et a1., 1980), and higher heart rates (Contrada et a1., 1982; Dembroski et al., 1979; Glass et a1., 1980) to stressful situations. It may we 11 be that the way in which Type As respond to stress contributes to their increased risk for CHD, making the study of physiological characteristics important.

While studies examining physiological characteristics of Type As are a relatively recent phenomenon, studies of the psychological characteristics of Type A persons are quite numerous. Experiments on construct validation of the Type A behavior pattern have indicated that, compared to Type Bs, Type As signal the passage of time sooner and work at a more rapid pace regardless of the presence of a time deadline (Burnam, Pennebaker, \& Glass, 1975), show more signs of irritation and impatience when performance is slowed down by a partner (Glass, Snyder, \& Hollis, 1974, Exp. 2), and act more aggressively when their sense of competence or mastery is threatened (Carver \& Glass, 1977 ).

Additional experimental studies have indicated that Type As put greater efforts into tasks and simultaneously underreport fatigue and other symptoms (Carver, Coleman, \& Glass, 1976; Weidner \& Matthews, 1978), and appear to be prone to giving up efforts to control after prolonged exposure to uncontrollable events (Brunson \& Mathews, 1981; Krantz, G1ass, \& Snyder, 1974). Additionally, Type As are better able to focus their attention on central tasks than Type Bs (Matthews \& Brunson, 1979; Lundberg, Warm, Seeman, \& Porter, 1980) and set higher aspirations for themselves (Ovcharchyn, Johnson, \& Petzel, 1981; Snow, 1978). In sum, the above experimental studies reinforce Glass's (1977) notion that Type A behavior can be conceptualized as a behavioral style aimed at asserting control over the environment. 
RESEARCH ON CHILDREN

While a large amount of research has been conducted on Type A behavior in adults, relatively little is known of its antecedents. According to recent observations, it appears that elements of Type A behavior are visible in 4-year-olds (G1ass, 1977, p. 154), and that the behavioral manifestations of Pattern A stabilize in late childfiood (Matthews, 1981, p. 237). One difference that does seem to exist between Type A adults and children is the stability of the behavior pattern. While Type A behavior is relatively stable among adults, researchers have found the Type A behavior pattern in children to increase with age (Wolf, Hunter, Webber, \& Berenson, 1981; Matthews \& Avis, in press).

Knowing how Type A behavior develops should offer insights into cardiovascular risk reduction in children as we 11 as in adults. This issue is particularly relevant since it is now we 11 recognized that the atherosclerotic process begins during the childhood years (Berenson et al., 1980; Strong \& McGil1, 1969). The following sections will review experimental literature on Type A behavior in children, preceded by an overview of the assessment measures. Then the physiological and psychological characteristics of Type A children will be discussed.

\section{Assessment of Type A Behavior in Children}

To date, several assessment measures of Type A behavior in children and adolescents have been validated. These include the Bortner $A-B$ index (Bortner \& Rosenman, 1967; Bortner, Rosenman, \& Friedman, 1970), the Adolescent Structured Interview (Siegel, Matthews, \& Leitch, 1981), the Butensky-Waldron interview (Butensky, Faralli, Heebner, \& Waldron, 1976), the Matthews Youth Test for Health (Matthews \& Angulo, 1980), and the Hunter-Wolf A-B Rating Scale (Wolf, Sklov, Wenzl, Hunter, \& Berenson, 1982). 
The Matthews Youth Test for Health (MYTH) and the HunterWolf $A-B$ Rating Scale are the two instruments most frequently used with children. The Hunter-Wolf $A-B$ Rating Scale is a self-administered measure. The MYTH, by contrast, is completed by an external observer, usually the child's teacher. (Both measures are discussed in greater detail in the Method section.) Because research on Type A behavior in children is relatively new, few comparisons between measures have been made. One purpose of the present study was to determine the relationship between the MYTH and the Hunter-Wolf A-B Rating Scale.

\section{Physiological Characteristics of Type A Children}

In studies of physiological characteristics of Type $A$ and $B$ children, results are mixed. Using the ButenskyWaldron interview to assess Type $A$ behavior, Buck and Stenn (1979) found no significant A-B differences in systolic blood pressure in a study of 94 hypertensive and normatensive adolescents. However, a study of 156710 - to 16-yearolds found that students with "Type A factors" (i.e., achievement orientation, intellectual orientation, order and control) had higher systolic and diastolic blood pressure levels than students characterized by a relative absence of Type A factors (Insel, Fraser, Phillips, \& Williams, 1981). Similar1y, Lawler, Allen, Critcher, and Standard (1981) also noted physiological differences in 41 Type $A$ and $B$ 11- and 12-year-olds, depending on the classification instrument used. Both male and female children classified as Type As by the Bortner Rating Scale showed significantly greater heart rate levels than Type Bs. When subjects were classified by the MYTH, Type A females showed lower mean heart rates and Type A males showed higher mean heart rates than Type Bs. In the above studies, physiological measures were collected under resting conditions. 
In three studies in which physiological measures were assessed under situations of behavioral challenge (i.e., a 10-minute unsignaled reaction time task and a 10-minute word task) or physical challenge (i.e., running), results were also inconsistent. Lawler and A1len's (1981) study of 3911 - to 13-year-old males and females indicated no A-B differences (as assessed by the Bortner Rating Scale and the MYTH) in systolic and diastolic blood pressure, heart rate, or skin conductance. The same investigators and their colleagues (Lawler et a1., 1981), using the identical behavioral challenge, found a number of physiological differences in 11- and 12-year-olds classified Type As or Bs. However, the results were again dependent on the classification instrument used. Both male and female children classified as Type As by the Bortner Rating Scale showed significantly greater heart rate reactivity to the tasks and skin conductance response magnitude to the reaction time signals. When subjects were classified by the MYTH, only Type A females showed larger increases in systolic blood pressure and heart rate to tasks, and faster reaction times. In a study of 15 male 3- to 6-yearolds, Lundberg (1983) also noted A-B physiological differences. Using a Swedish translation of the MYTH to classify children by Type, he found that Type A boys had significantly greater increases in systolic blood pressure during a challenging running task than Type B boys.

In summary, the data on the physiological responses of Type A children are inconsistent and difficult to explain. Consistent age or sex trends are not apparent; consistent results across assessment instruments or tasks are not obtained either. More research is necessary to sort out the discrepancies in this area. 
Construct Validation. In contrast to studies of physiological responses, studies examining the psychological characteristics of Type A children are more clear cut. Experiments on construct validation have indicated that Type As are more aggressive and impatient than their Type B counterparts (Matthews \& Angu1o, 1980), and are more competitive (Wolf et a1., 1982). As Type A adults (Glass, 1977), Type A children initially respond to highly salient uncontrollable events with more efforts to assert control than Type Bs (Matthews, 1979). Additionally, both Type A adults and children ignore fatigue while performing a strenuous task (Carver, Coleman, \& Glass, 1976; Matthews \& Volkin, 1981; Weidner \& Matthews, 1978).

While research has not directly examined Type A and achievement in children, several studies have explored this component of Type A behavior indirectly. Experimental studies have shown that Type A fourth- and sixth-graders make greater efforts to excel than Type Bs on tasks that have ambiguous performance criteria (Matthews \& Volkin, 1981). For example, Type A fourth-graders solved a greater number of simple arithmetic problems than Type Bs when no time deadiine was given. In a second "no-deadiine" experiment, male Type A sixth-graders held a weight $50 \%$ longer than Type Bs. An additional study (Matthews \& Siegel, 1983) examined the impact of performance standards on the social comparison behaviors of Type A and B fourthgraders. Children were asked to perform a creativity task that had five trials. Half of the children were given an explict standard by which to evaluate their performance prior to each trial; half were given no standard. In between trials, children had the opportunity to compare their performance with that of hypothetical coactors. After the five trials were completed, all subjects were informed that their total score represented the middle score of 11 tested children and were asked to select the score of another child for examination. Results indicated 
that the Type A children, when comparing themselves to a standard of performance, chose to evaluate their performance against a top-scoring coactor regardless of the presence or absence of an explicit standard. Type Bs only chose to evaluate their performance against a top-scoring coactor in the absence of an explicit standard. While not directly addressing achievement in Type A children, these studies indicate that Type A children do make greater efforts to excel and are more concerned with their performance than Type B children.

In contrast to the literature on Type $A$ and achievement in children, research with adults and adolescents has directly examined this area. As might be expected, academic achievement is positively correlated with Type A behavior in adults and adolescents (Glass, 1977, pp. 39 42 ; Matthews, Helmreich, Beane, \& Lucker, 1980 ; Ovcharchyn, Johnson, \& Petze1, 1981; Waldron et a1., 1980). Ovcharchyn et al. (1981), for example, report that with respect to academic achievement, Type A students "tend to have more articulated goals and interests than their Type B counterparts" (p. 253).

Type A and Goal-Setting Behavior. Although studies of Type A behavior in children have examined a number of relevant psychological characteristics, one facet of Type A behavior that has not been explored in children is goalsetting behavior. Goal-setting studies with children in general have found that aspiration levels are tied to a child's self-concept (Bernstein, 1975) and ego-involvement in a task (Sears, 1940). It appears that self-confident and successful children have higher aspirations than children who are unsuccessful or lack self-confidence (Sears, 1940). There is some evidence that adult Type As are more self-confident than Type Bs (Glass, 1977, p. 185). Since adult Type As tend to be higher achievers than Type Bs, Type As might also set higher goals for themselves than 
Type Bs.

Support for the above hypothesis comes from a study by Snow (1978). In a level-of-aspiration study with adult males, Snow (1978) used a procedure in which he had Type As and Bs complete a series of puzzles. Prior to the start of each puzzle participants noted how much of the task they would try to complete in the allotted time period. His results showed that these values, or aspiration levels, were significantly higher for Type A men than for Type $B$ men, although actual performance levels were equivalent. Snow concluded that the competitive achievement striving of Type A men, perhaps one way of asserting control over the environment, did indeed result in significantly higher goa1-setting.

Since Type A children behave similarly to Type A adults on a variety of measures, it is conceivable that Type A children might also set higher goals for themselves than Type B children. One purpose of this study was to determine if the goal-setting behaviors of male and female Type $A$ and $B$ children are similar to the goal-setting behaviors reported for adult male Type As and Bs.

\section{Parental Correlates of Type A Behavior in Children.}

Research on twins examining the origins of Type A behavior seems to suggest that the behavior pattern is largely socialized. For example, in a correlational study of 93 pairs of monozygotic and 97 pairs of dizygotic middle-aged male twins, Rahe, Herwig, and Rosenman (1978), using heritability estimates, found the Type A behavior pattern to be noninheritable. That is, although Type A behavior was significantly correlated between sibling pairs, Type A behavior in monozygotic twins did not correlate significantly higher than Type A behavior in dizygotic twins. Rahe et a1. (1978) note that "this significant concordance for monozygotic and dizygotic twins presumably reflected 
behaviors developed from early critical learning experiences" (p. 482).

The suggestion that Type A behavior is learned is partially supported by a study of Type A behavior in twins and their parents. Matthews and Krantz (1976) found male twins to be more similar to their fathers than to their mothers in behavior Type. Female twins were more similar to their mothers than to their fathers, although correlations were weaker than those obtained from males in the sample. An additional study of male adolescents and their fathers (Bortner, Rosenman, \& Friedman, 1970) examined the similarity of father and son $A-B$ classifications. These researchers found a significant positive correlation between father and son $A-B$ ratings. These two studies also suggest that Type A behavior is learned.

Research based on behavioral observations and on selfreports has also provided some information on parental correlates of Type A behavior in children. In a study of Type A behavior in college students (Waldron et a1., 1980), Type A men (when compared to Type Bs) recalled their fathers as having been more severe, having punished them more often physically, and having made them feel resentful rather than guilty when punished. Type A women recalled their mothers as having punished them more often physically. An experimental investigation based on observations of mothers and sons suggested that mothers of Type A sons tend to be critical of their child's performance and repeated1y push them to do better (Matthews, Glass, \& Richins, 1977).

In sum, although there is some evidence that Type $A$ behavior is learned and that parents treat Type A children differently than Type B children, it is not clear what specific parental behaviors encourage the development of Type A behavior. The present study examined parental aspirations and expectations for Type A and Type B children in order to determine if parents of Type A children report 
having higher aspirations for their offspring than parents of Type B children.

To conclude, the present investigation attempted to answer the following three questions:

1. What is the relationship between the MYTH and the Hunter-Wolf A-B Rating Scale?

2. Do Type A male and female children set higher aspirations for themselves than Type B children?

3. Do parents of Type As set higher goals for their offspring than parents of Type Bs?

Consistent with recent findings based on adult male Type As (Snow, 1978), it was expected that Type A children would set higher goals for themselves than Type Bs. Further, it was predicted that parents of Type A children would report having higher aspirations for their offspring than parents of Type B children. 


\section{CHAPTER II}

METHOD

\section{SUBJECTS}

The subjects were 41 female and 32 male 9-to 12-yearold children and their parents. Subjects were recruited from the fourth, fifth, and sixth grade classes of a private grade school in the Northwest. Parents of all the children in these grades were contacted by letter, asked to allow their children to participate in the research, and requested to participate themselves. Seventythree parents ( $83 \%$ ) agreed to allow their children to participate. Thirty-seven mothers (62\%) and 27 fathers ( $53 \%$ ) agreed to participate themselves, and completed questionnaires. Due to illness on the day of the experiment, two male and seven female children did not participate in the study. Thus, the subjects of the present study were 30 male and 34 female children. ${ }^{I}$

\section{ASSESSMENT OF TYPE A BEHAVIOR}

Type A behavior of the students was assessed by the Matthews Youth Test for Health (MYTH)(Matthews \& Angulo, 1980). The MYTH is a 17-item questionnaire to be completed by teachers. Examples of items include "When this child plays games, he/she is competitive," and "This child gets irritated easily." Ratings were made on 5-point scales. A score of 1 indicates that a statement is extremely uncharacteristic of a child; a score of 5 denotes an extremely characteristic statement. Possible total MYTH 
scores range from 17 (extreme Type B) to 85 (extreme Type A). Items of the MYTH cluster around two primary factors: "competitiveness" and "impatience-aggression." Children's summed scores of all items and the factors were used in the analyses. The MYTH has a test-retest reliability ranging from .48 to .55 (across 1 year) (Lundberg, 1983; Matthews \& Avis, in press) to .83 (across 3 months). It is an interna11y consistent instrument $(\alpha=.90)$, and there is considerable evidence of its validity (Mathews \& Angulo, 1980). (See Appendix B for a copy of the MYTH.) A second classification instrument used was the Hunter-Wolf A-B Rating Scale (Wolf et al., 1982). This self-report measure consists of 24 items reflecting major components of Type A behavior. All items were rated on 7-point scales. Examples of items include "I drink slowly--I drink fast" and "I am never a leader in activities-I am always a leader in activities." The scale yields the following factors: "eagergy" (eagerness-energy), "restlessness-aggression", "leadership", and "alienation." Test-retest reliability of the Hunter-Wolf is .53 (across 6 weeks). Partial support for the validity of the instrument is reported by Wolf et al. (1982). (See Appendix B for a copy of the Hunter-Wolf Rating Scale.)

\section{ASSESSMENT OF PARENTAL ASPIRATIONS}

Parental aspirations were assessed by a two-page self-administered questionnaire. The questionnaire asked both parents to independently rate (on 7-point scales) the educational aspirations they have for their child, their goal-setting behaviors toward their child, and how they perceive their child's reactions to their goals. Parental responses on this questionnaire were examined as predictors of children's Type A behavior. (See Appendix C for a copy of the Parental Information Form.) 


\section{ASSESSMENT OF CHILDREN'S ASPIRATIONS}

Children's goal-setting was assessed by means of five "Connect the Numbers" puzzles (Raynor \& Smith, 1966 ; Snow, 1978). (See Appendix C for copies of these puzzles.)

This task was chosen because it is not generally frustrating, and because it is not related to academic ability, a potentially confounding variable. A pilot test of the puzzles with 9- and 10-year-olds indicated suitability for this age group. The five puzzles were of similar difficulty and consisted of the numbers 1 to 80 arranged randomly on a page. The task was to connect the numbers consecutively, beginning with the number 1 , as fast as possible, reaching the highest number possible in the allotted time. Subjects were given 15 seconds to review each puzzle prior to working it, and $I$ minute to work it. This was the identical procedure employed by snow (1978).

Dependent Measures

Prior to starting each puzzle, subjects estimated which number they would try to reach on that puzzle, and recorded that number at the top of the page. This measure served as the level of aspiration. Other dependent measures recorded include puzzle performance, the actual number reached by a subject; attainment discrepancy, the difference between a subject's puzzle performance and aspiration level; and goal discrepancy, the level of aspiration for a puzzle minus the attainment score on the previous puzzle.

\section{PROCEDURE}

Informed consents of the institution, teachers, and parents were obtained prior to having contact with the children. (See Appendix A for copies of the consent forms.) 
Three weeks before the investigator met with the children, teachers were contacted and given copies of the MYTH to complete. The teachers were "blind" to the focus of the study and to the hypotheses being tested. At approximately the same time, parents were mailed a detailed packet about the research project. This packet contained a cover letter explaining the nature of the project, a letter from the school principal informing parents of institutional approval, consent forms for each parent, a Parental Information Form for each parent, and a stamped return envelope addressed to the principal investigator. Parents were asked to respond within 10 days. After 10 days had elapsed, the investigator telephoned slow respondents twice or until they indicated that they did not wish to participate.

One week before contact with the children, copies of the MYTH were collected from the teachers. In order to remain "blind" to the children's Type A ratings, the investigator did not score the MYTHs until the data had been collected from all children.

Once informed consents were obtained and the MYTH and Parental Information Forms were completed and returned, the principal investigator visited the school to conduct the experiment. Data were collected from the fourth, fifth, and sixth grade classrooms separately on the same morning. Each classroom had approximately 20 students participating in the study (varying from 15 to 25). In each classroom the investigator explained the nature of the study to the children and obtained their informed consent to participate. After the students completed the Hunter-Wolf $A-B$ Rating scale the goal-setting task was administered. (See Appendix D for the experimental instructions.) After completion of the tasks, subjects were debriefed according to the APA (1981) ethical principles of psychologists, and praised for their performance. (See Appendix D for the debriefing procedure.) 


\section{CHAPTER III}

\section{RESULTS}

The medians, means, and standard deviations of the MYTH for boys and girls are presented in Table I. Consistent with findings reported by Matthews and Angulo (1980), teachers assessed boys to be more Type A (M = 55.2) than girls $(\underline{M}=43.4), \underline{t}(62)=16.42, \underline{p}<.01$. A different pattern of response was reflected in the Hunter-Wolf ratings. As can be seen in Table II, boys did not rate themselves to be more Type A $(\underline{M}=96.9)$ than did girls $(\underline{M}=91.9)$, $\underline{t}(62)=1.88, \underline{p}>.05$. This finding is also consistent with past research (Wolf et al., 1982) which found no sex differences in self-ratings of Type A behavior.

\section{CORRELATIONS BETWEEN THE ASSESSEMNT INSTRUMENTS}

The correlations between the MYTH Type A ratings and the Hunter-Wolf Type A ratings for both sexes combined was marginally significant, $\underline{r}=.21, \underline{p}<.10$. As can be seen in Tables III and IV, however, when correlations between instruments were examined for each sex, these correlations were not significant $(\underline{r}=.09, \underline{p}>.10$ for males; $\underline{r}=.19$, $\underline{p}>.10$ for females). Similar factors of the two instruments -- Factor 2 (impatience-aggression) of the MYTH and Factor 1 (restlessness-aggression) of the Hunter-Wolf - were marginally correlated $(\underline{r}=.32, \underline{p}<.10)$ in females on $1 \mathrm{y}$.

In contrast, correlations within each of the instruments were highly significant. As reflected in Tables III and IV, MYTH Type A ratings correlated significantly with 
TABLE I

MEDIANS, MEANS, AND STANDARD DEVIATIONS OF THE MATTHEWS YOUTH TEST FOR HEALTH FOR BOYS AND GIRLS

$$
\text { Boys }(N=30) \text { Girls }(N=34) \underline{t} \quad \underline{p}
$$

MYTH Type A score

$\begin{array}{llcll}\text { Median } & 55.50 & 43.83 & & \\ \text { Mean : } & 55.23 & 43.44 & 16.42 & .01 \\ \text { SD } & 10.99 & 12.14 & & \end{array}$

MYTH Factor 1 Score

(competitiveness)

$\begin{array}{lrrrr}\text { Median } & 26.90 & 23.50 & & \\ \text { Mean } & 26.83 & 22.68 & 7.26 & .01 \\ \text { SD } & 5.33 & 6.80 & & \end{array}$

MYTH Factor 2 Score

(impatience-aggression)

$\begin{array}{lrrrr}\text { Median } & 30.00 & 18.10 & & \\ \text { Mean } & 28.40 & 20.65 & 15.05 & .05 \\ \text { SD } & 8.10 & 7.87 & & \end{array}$

$a_{\text {Range }}=17-85$. Higher scores indicate greater

Type A behavior.

$$
{ }^{b} \text { Range }=8-40 \text {. Higher scores indicate greater }
$$

competitiveness.

$c_{\text {Range }}=9-45$. Higher scores indicate greater impatience-aggression. 
MEDIANS, MEANS, AND STANDARD DEVIATIONS OF THE HUNTER-WOLF A-B RATING SCALE FOR BOYS AND GIRLS

$$
\text { Boys }(N=30) \text { Girls }(N=34) \text { t } \underline{p}
$$

Hunter-Wolf Type A Score ${ }^{a}$

$\begin{array}{llll}\text { Median } & 94.50 & 92.50 & \\ \text { Mean } & 96.87 & 91.91 & 1.88 \mathrm{n.s} . \\ \text { SD } & 12.51 & 15.94\end{array}$

Hunter-Wo1f Factor 1 Score

$\begin{array}{llccc}\left(\begin{array}{l}\text { restlessness }- \\ \text { aggression) }\end{array}\right. & \text { Median } & 31.50 & 29.83 & \\ & \text { Mean } & 32.10 & 29.94 & 1.06 \text { n.s. } \\ & \text { SD } & 7.73 & 8.90\end{array}$

Hunter-Wolf Factor 2 Score

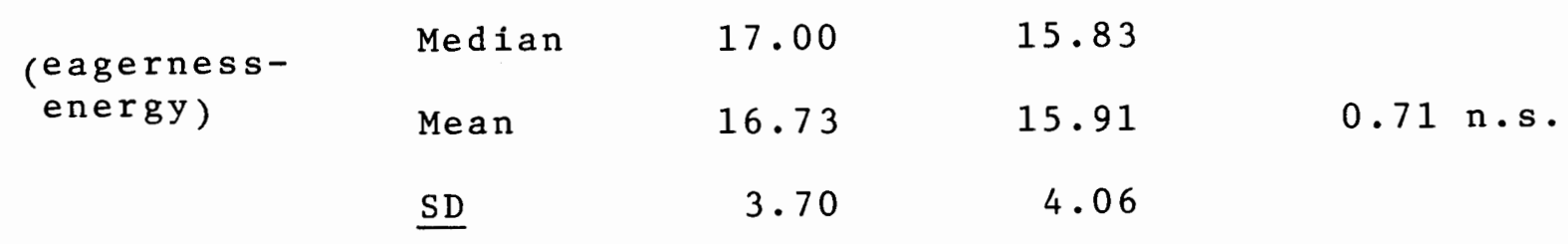

Hunter-Wolf Factor 3 Score

\begin{tabular}{|c|c|c|c|c|}
\hline \multirow{3}{*}{ (leadership) } & Median & 7.25 & 6.10 & \multirow{3}{*}{$0.43 \mathrm{n.s}$. } \\
\hline & Mean & 7.33 & 6.82 & \\
\hline & SD & 3.07 & 3.12 & \\
\hline
\end{tabular}

Hunter-Wolf Factor 4 Score
(alienation)
Median
13.50
11.50
Mean
13.27
12.12
$1.65 \mathrm{n} . \mathrm{s}$.

\section{$\underline{\mathrm{SD}}$}

$a_{\text {Range }}=24-168$. Higher scores indicate greater Type A behavior. 


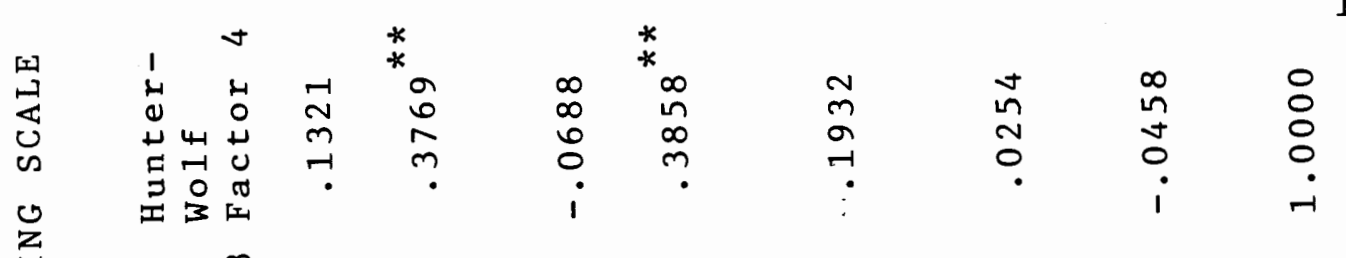

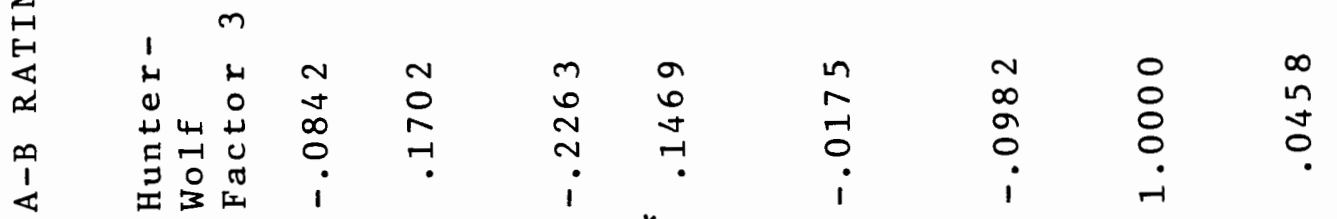

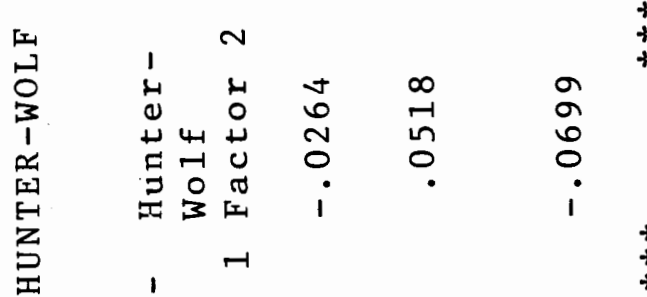

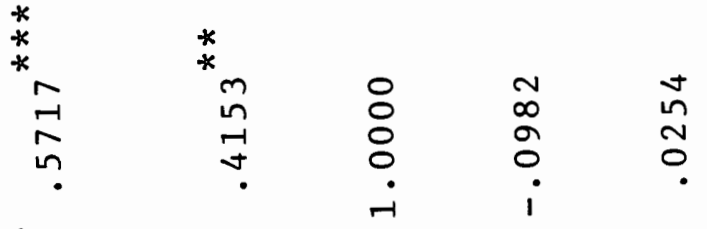

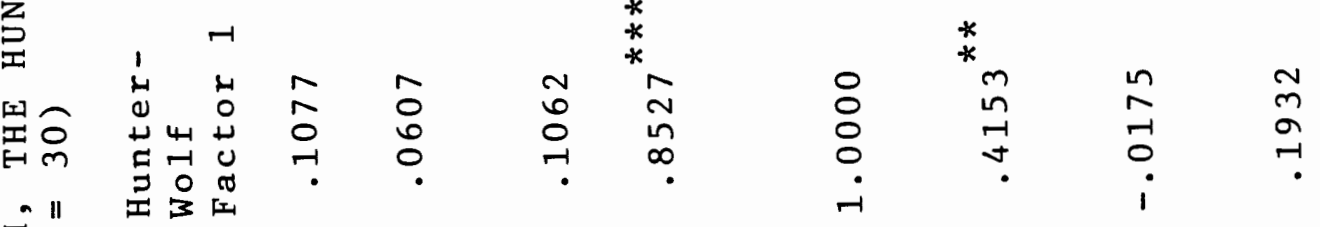

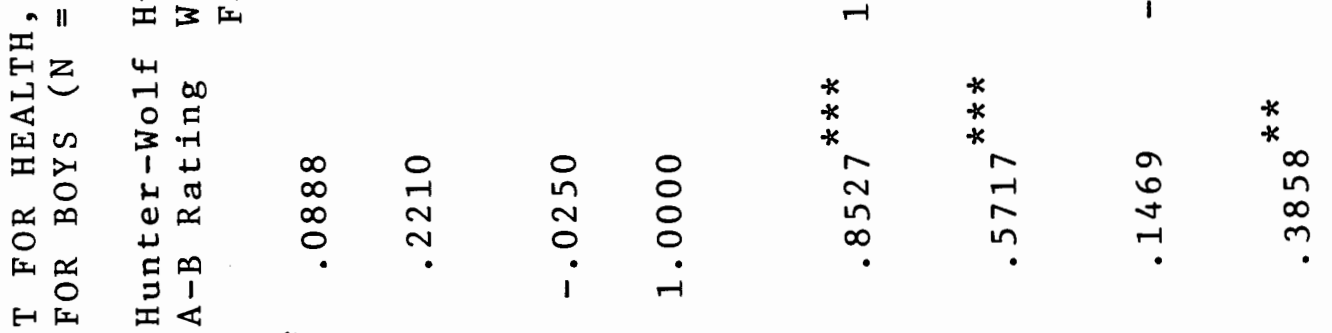

四 H王 至

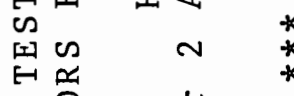

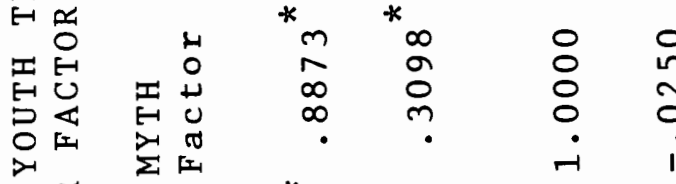

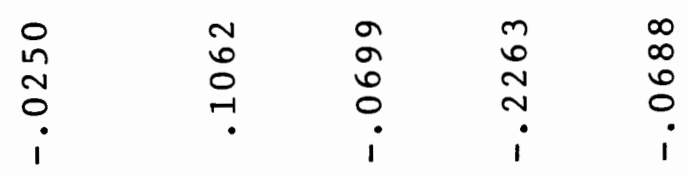

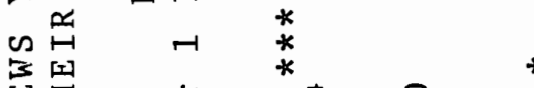

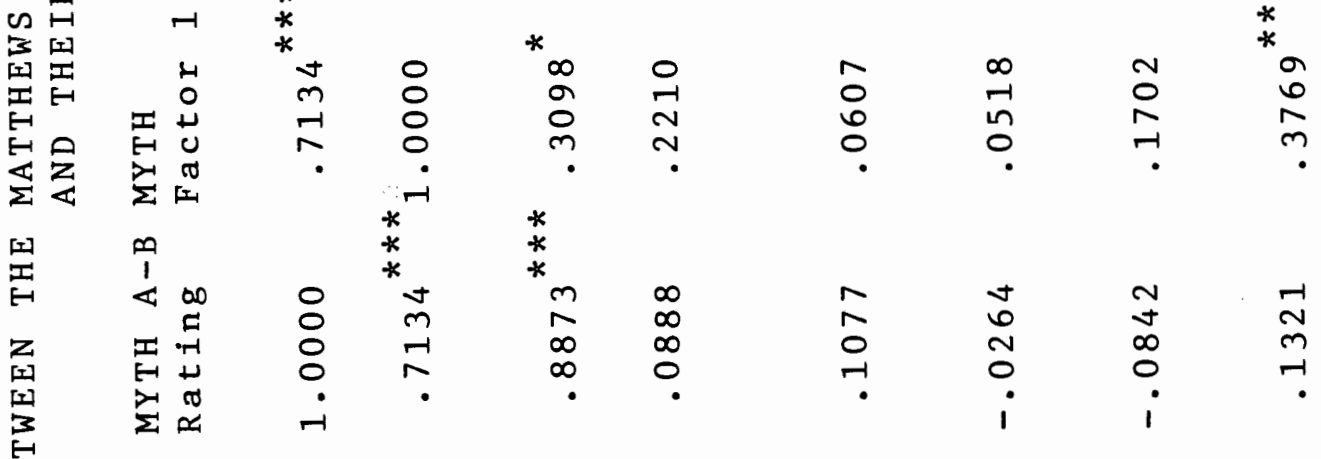

님

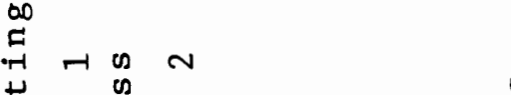

201

H。 U⿺

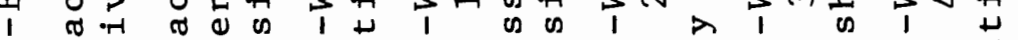

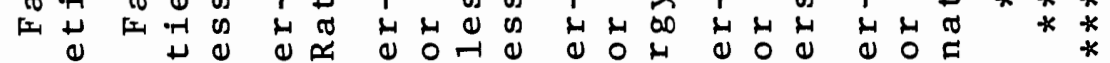

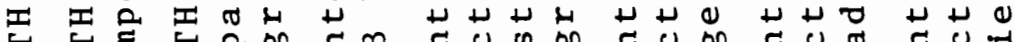

0 in -

$+00$

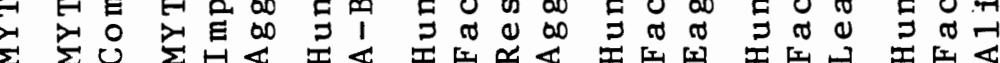




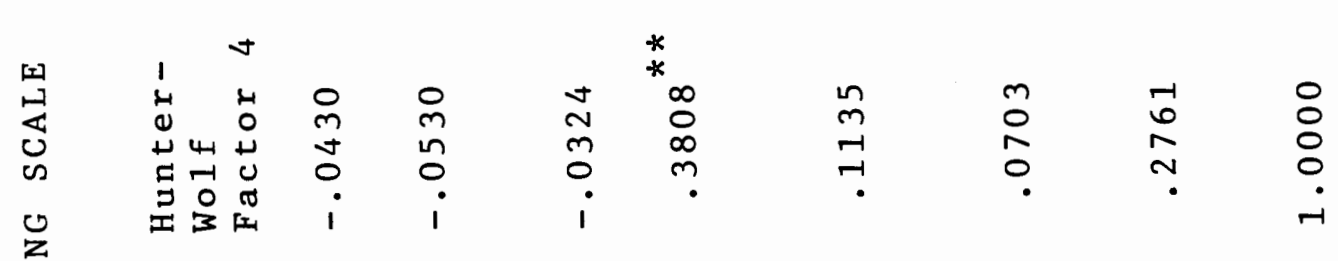

$\stackrel{H}{\mathrm{E}}$

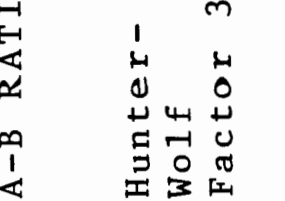

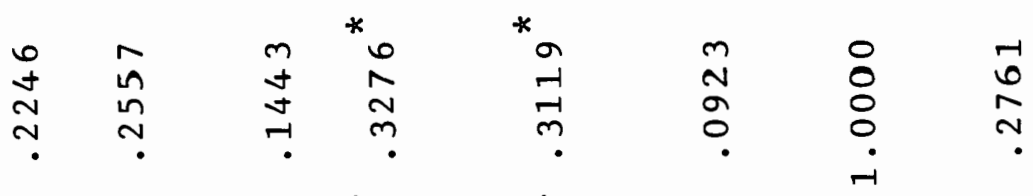

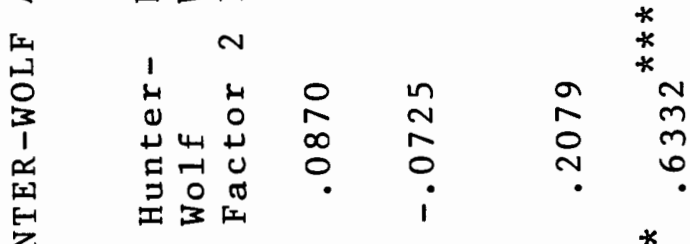

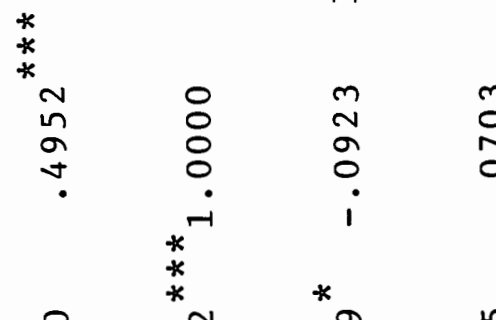

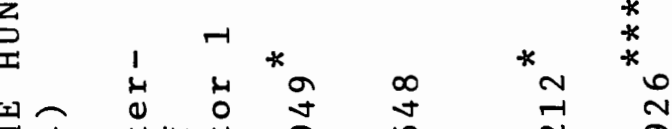

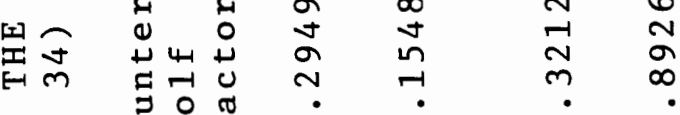

a II至运

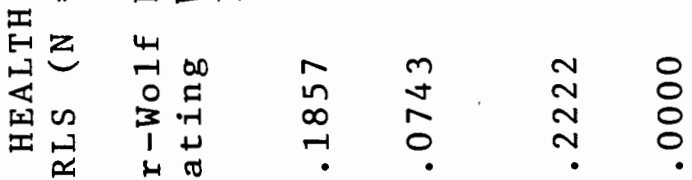

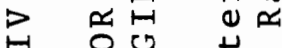

I

红

的圷

됨ㅇ

평

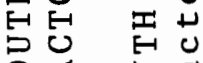

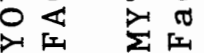

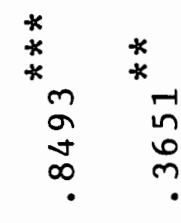

$\begin{array}{ll}-1 & 1 \\ 0 & N \\ 0 & N\end{array}$

$\underset{\sim}{*} \underset{\sim}{\sim}$

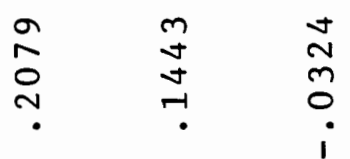

舟告

${ }^{*}+\infty{ }^{*} \quad{ }^{*}$

되 되

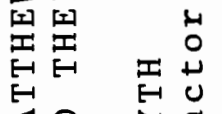

*

会尖

되

1

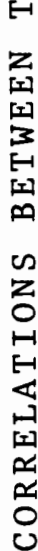

य

至

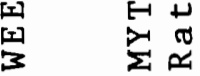

$\begin{array}{lll}\infty & 0 \\ \infty & 0 \\ 2 & 0 \\ r & 0 \\ & * & * \\ & * & * \\ 0 & * & * \\ 0 & * & *\end{array}$

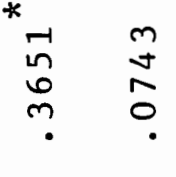

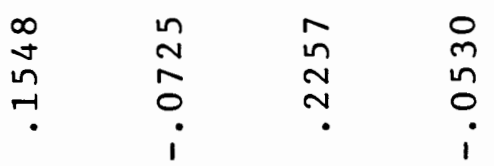

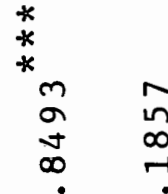

*

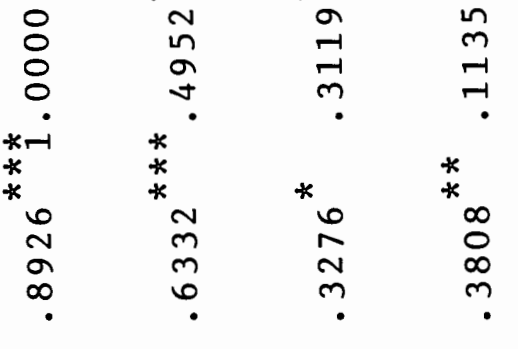

$\begin{array}{ll}0 & \infty \\ 0 & \infty \\ 0 & \Omega \\ 0 & 1\end{array}$

$n$
$1 n$
$\infty$
$r-1$

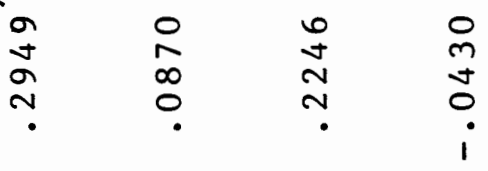

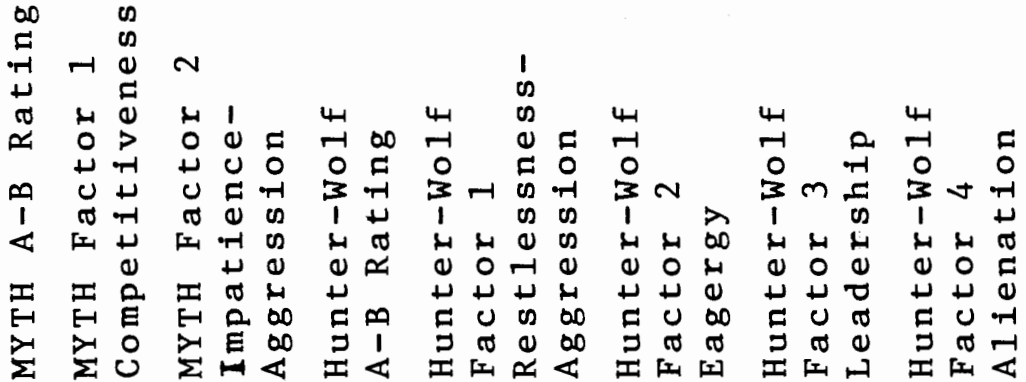

O n

ivi

이이 이

$* *$ 
MYTH Factor $1(\underline{r}=.71, \mathrm{P}<.01$ for males; $\underline{\mathrm{r}}=.80, \underline{\mathrm{p}}<.01$ for females) and with MYTH Factor 2 ( $\underline{r}=.89, \underline{p}<.01$ for males; $\underline{r}=.85, \underline{p}<.01$ for females). Similarly, the Hunter-Wolf Type A ratings correlated significantly with Factor $1(\underline{r}=.85, \underline{p}<.01$ for males; $\underline{r}=.89, \underline{p}<.01$ for females), Factor $2(\underline{r}=.57, \underline{p}<.01$ for males $\underline{r}=.63$, $\underline{\mathrm{p}}<.01$ for females), and Factor $4(\underline{\mathrm{r}}=.39, \underline{\mathrm{p}}<.05$ for males; $\underline{r}=.38, \underline{\mathrm{p}}<.05$ for females). Factor 3 was marginally correlated with the Hunter-Wolf Type A rating $(\underline{r}=.33, \underline{p}<.10)$ in females only.

Because we have more information on the reliability and validity of the MYTH than on the Hunter-Wolf $A-B$ Rating Scale, the analyses reported below employed the MYTH as the primary classification measure. Analyses were also performed using the Hunter-Wolf scale as a classification instrument. Where results based on the Hunter-Wolf assessment of Type A behavior differ from those of the the MYTH they will be noted.

\section{CHILDREN'S ASPIRATIONS AND PERFORMANCE}

It was expected that the results of Snow's (1978) study would replicate in a sample of male and female children. Recall that snow found adult male Type As to have higher aspirations than adult male Type Bs. Identical to Snow's statistical procedure, a series of t tests were used to analyze the children's aspirations and performance levels. The independent variable was the children's Type A or B score. ${ }^{2}$ All analyses were conducted separately for males and females. As can be seen in Tables $V$ and VI, neither Type A males nor Type A females exhibited higher aspiration levels than their same-sex counterparts on any of the puzzles (tss $(29) \leq .94$, ps $>.10$ for males on all puzzles; tss $(33) \leq 1.28$, ps $>.10$ for females on all puzzles). Results were similar when based on the Hunter-Wolf 
TABLE $V$

LEVEL OF ASPIRATION FOR MALE TYPE A AND B CHILDREN ON PUZZLES $1-5$

\begin{tabular}{|c|c|c|c|c|c|c|}
\hline Puzzle & Type & & $\underline{M}$ & $\underline{S D}$ & $\underline{t}$ & $\underline{\mathrm{p}}$ \\
\hline \multirow[b]{2}{*}{1} & Type & A & 47.73 & 19.31 & 0.33 & $\mathrm{n} \cdot \mathrm{s}$. \\
\hline & Type & B & 51.60 & 17.56 & & \\
\hline \multirow[b]{2}{*}{2} & Type & A & 33.87 & 16.27 & 0.001 & $\mathrm{n} \cdot \mathrm{s}$. \\
\hline & Type & B & 33.73 & 9.10 & & \\
\hline \multirow[b]{2}{*}{3} & Type & A & 31.53 & 17.50 & 0.34 & $\mathrm{n} \cdot \mathrm{s}$. \\
\hline & Type & B & 28.40 & 11.30 & & \\
\hline \multirow{2}{*}{4} & Type & A & 32.33 & 17.56 & 0.70 & $\mathrm{n} . \mathrm{s}$. \\
\hline & Type & B & 27.07 & 16.93 & & \\
\hline \multirow[b]{2}{*}{5} & Type & A & 32.27 & 16.75 & 0.94 & $\mathrm{n} \cdot \mathrm{s}$. \\
\hline & Type & B & 27.40 & 9.94 & & \\
\hline \multirow{2}{*}{$\begin{array}{c}\text { Mean } \\
\text { Puzzle } \\
\text { Data }\end{array}$} & Type & $\mathrm{A}$ & 34.67 & 16.56 & 0 & $\mathrm{n} \cdot \mathrm{s}$. \\
\hline & Type & B & 34.60 & 10.97 & & \\
\hline
\end{tabular}

Note. $N=30$. Matthews Youth Test for Health (MYTH) scores were split on the median to classify by Type, resulting in 15 Type As and 15 Type Bs. 


\section{TABLE VI}

LEVEL OF ASPIRATION FOR FEMALE TYPE A AND B CHILDREN ON PUZZLES $1-5$

\begin{tabular}{|c|c|c|c|c|c|c|}
\hline $\mathrm{Puzzle}$ & \multicolumn{2}{|c|}{ Type } & $\underline{\mathbf{M}}$ & $\underline{S D}$ & $\underline{t}$ & $\underline{\mathrm{p}}$ \\
\hline \multirow{2}{*}{1} & Type & A & 54.07 & 24.69 & 1.28 & n.s. \\
\hline & Type & B & 44.74 & 23.29 & & \\
\hline \multirow[t]{2}{*}{2} & Type & A & 37.80 & 15.23 & 0.08 & $\mathrm{n} \cdot \mathrm{s}$. \\
\hline & Type & B & 36.12 & 18.87 & & \\
\hline \multirow[b]{2}{*}{3} & Type & A & 32.26 & 17.20 & 0.007 & $\mathrm{n} \cdot \mathrm{s}$. \\
\hline & Type & B & 32.79 & 18.80 & & \\
\hline \multirow{2}{*}{4} & Type & A & 26.80 & 8.36 & 0.12 & $\mathrm{n} \cdot \mathrm{s}$. \\
\hline & Type & B & 28.26 & 14.73 & & \\
\hline \multirow[b]{2}{*}{5} & Type & A & 25.33 & 6.34 & 0.40 & $\mathrm{n} \cdot \mathrm{s}$. \\
\hline & Type & B & 27.95 & 14.99 & & \\
\hline \multirow{2}{*}{$\begin{array}{c}\text { Mean } \\
\text { Puzzle } \\
\text { Data }\end{array}$} & Type & A & 36.73 & 11.97 & 0.36 & $\mathrm{n} \cdot \mathrm{s}$. \\
\hline & Type & B & 33.89 & 14.93 & & \\
\hline
\end{tabular}

Note. $N=34$. Matthews Youth Test for Health (MYTH) scores were split on the median to classify by Type, resulting in 17 Type As and 17 Type Bs. 
assessment of Type A behavior. Thus, Snow's findings did not replicate in a sample of Type $A$ and $B$ children.

Significant differences due to Type A females were obtained on the performance data. While male Type As and Bs did not differ with respect to puzzle performance (ts (29) $\leq .55$, ps $>.10$ on all puzzles) ${ }^{3}$, female Type As did perform at significantly higher levels than female Type Bs $(\underline{t}(33)=7.78, \underline{p}<.008$ on puzzle $1 ; \underline{t}(33)=3.37, \underline{p}<.08$ on puzzle $4 ; \underline{t}(33)=2.74, \underline{p}<.10$ on puzzle $5 ; \underline{t}(33)=5.00$,

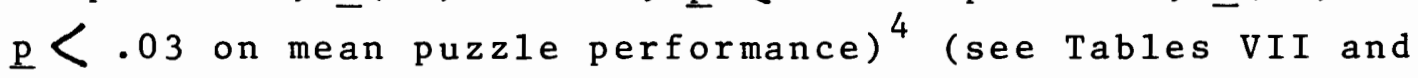
VIII). Female Type As did not outperform male Type As on any puzzle, ts $(31) \leq 1.32$, ps $>.10$. No significant results were obtained for attainment discrepancy or goal discrepancy values. Results obtained for boys in the current study parallel those of snow (1978) who found no performance differences among Type $A$ and $B$ men.

\section{PARENTAL ASPIRATIONS}

It was hypothesized that parents would report having higher aspirations for their Type A children than for their Type B children. Bivariate correlations between Type A scores and parental questionnaire responses are presented in Table IX. As can be seen from this table, mothers who perceived themselves as setting higher goals than other mothers had children who scored high on Type A behaviors, $\underline{r}=.31, p<.06$. The remaining items were not significantly related to Type A behavior in children. No significant correlations were found for fathers.

In order to determine how much variance in Type $A$ behavior could be accounted for by parental aspirations, the questions most strongly related to Type A scores were entered into multiple regression equations as predictor variables. 5 These variables are also noted in Table IX. For mothers, the following two predictors 
PUZZLE PERFORMANCE FOR MALE TYPE A AND B CHILDREN ON PUZZLES 1 - 5

\begin{tabular}{|c|c|c|c|c|c|c|}
\hline Puzzle & Type & & $\underline{M}$ & $\underline{\mathrm{SD}}$ & $\underline{t}$ & $\underline{p}$ \\
\hline \multirow{2}{*}{1} & Type & A & 29.27 & 5.45 & 0.41 & n.s. \\
\hline & Type & B & 30.60 & 5.84 & & \\
\hline \multirow{2}{*}{2} & Type & A & 23.26 & 9.79 & 0.06 & n.s. \\
\hline & Type 1 & B & 23.93 & 4.45 & & \\
\hline \multirow[b]{2}{*}{3} & Type & A & 25.60 & 8.52 & 0.05 & $\mathrm{n} . \mathrm{s}$. \\
\hline & Type & B & 26.20 & 5.54 & & \\
\hline \multirow[b]{2}{*}{4} & Type & A & 25.40 & 8.16 & 0.55 & $\mathrm{n} \cdot \mathrm{s}$. \\
\hline & Type & B & 27.40 & 4.62 & & \\
\hline \multirow[b]{2}{*}{5} & Type & A & 32.80 & 9.78 & 0.03 & $\mathrm{n} \cdot \mathrm{s}$. \\
\hline & Type & B & 33.33 & 7.75 & & \\
\hline \multirow{2}{*}{$\begin{array}{c}\text { Mean } \\
\text { Puzzle } \\
\text { Data }\end{array}$} & Type & A & 26.87 & 8.48 & 0.29 & $\mathrm{n} . \mathrm{s}$. \\
\hline & Type & B & 28.13 & 3.31 & & \\
\hline
\end{tabular}

Note. $N=30$. Matthews Youth Test for Health (MYTH) scores were split on the median to classify by Type, resulting in 15 Type As and 15 Type Bs. 
PUZZLE PERFORMANCE FOR FEMALE TYPE A AND B CHILDREN ON PUZZLES $1-5$

\begin{tabular}{|c|c|c|c|c|c|c|}
\hline Puzzle & Type & & $\underline{M}$ & $\underline{\mathrm{SD}}$ & $\underline{t}$ & $\underline{p}$ \\
\hline \multirow[t]{2}{*}{1} & Type & A & 28.86 & 5.22 & 7.78 & .008 \\
\hline & Type & B & 23.68 & 5.50 & & \\
\hline \multirow[t]{2}{*}{2} & Type & A & 23.20 & 6.09 & 2.35 & $\mathrm{n} . \mathrm{s}$. \\
\hline & Type & B & 20.21 & 5.28 & & \\
\hline \multirow[b]{2}{*}{3} & Type & $\mathrm{A}$ & 25.27 & 6.48 & 1.33 & $\mathrm{n} \cdot \mathrm{s}$. \\
\hline & Type & B & 22.79 & 6.01 & & \\
\hline \multirow[b]{2}{*}{4} & Type & A & 27.80 & 4.96 & 3.37 & .08 \\
\hline & Type & B & 23.53 & 7.86 & & \\
\hline \multirow{2}{*}{5} & Type & $\mathrm{A}$ & 33.87 & 7.29 & 2.74 & .10 \\
\hline & Type & $\mathrm{B}$ & 29.32 & 8.44 & & \\
\hline \multirow{2}{*}{$\begin{array}{c}\text { Mean } \\
\text { Puzzle } \\
\text { Data }\end{array}$} & Type & $\mathrm{A}$ & 27.87 & 2.85 & 5.00 & .03 \\
\hline & Type & B & 24.16 & 5.89 & & \\
\hline
\end{tabular}

Note. $N=34$. Matthews Youth Test for Health (MYTH) scores were split on the median to classify by Type, resulting in 17 Type As and 17 Type Bs. 
CORRELATIONS BETWEEN THE MATTHEWS YOUTH TEST FOR HEALTH AND MOTHERS' AND FATHERS' RESPONSES ON THE PARENTAL INFORMATION FORM

$$
\text { Questionnaire Item }
$$

Parent

Mother Father

1. Do you set educational goals for your child?

2. If you set goals for your child, how would you compare them to goals other parents set for their children?

3. Do you think goal-setting in general is valuable?

4. How would you rate your child's ability compared to other children

5. What is the highest educational level you want to see your child achieve?

6. Does your child complain about the goals you set for him or her?

7. Does your child attain the goals you set for him or her?

8. Does your child know what you expect from him or her?

$\begin{array}{cc}.03 & -.19 \\ .31^{* a} & -.08 \\ -.07 & .02 \\ -.09 & -.02 \\ 0 & .21^{\mathrm{a}} \\ -.23 & -.09 \\ -.23^{\mathrm{a}} & -.17 \\ .12 & .23^{\mathrm{a}}\end{array}$

Note. Bivariate correlations are based on 37 mothers and 27 fathers.

${ }^{*} \underline{p}<.06$

a Used as predictors of Type A behavior in the regression analyses. 
were entered into the regression equations: (1) mothers' reports that they set higher goals for their children compared to other mothers $(\underline{r}=.31)$, and (2) mothers' perceived goal attainment by their children $(\underline{r}=-.23)$. For regression analyses involving the fathers, the following two predictors were entered into regression equations: fathers' reported educational aspirations for their children $(\underline{r}=.21)$, and (2) fathers' reports that their children know what is expected of them $(\underline{r}=.23)$. Type A scores were regressed on these predictor variables. Analyses were conducted separately for each sex. 6

Tables $X$ and $X I$ present the results of the stepwise solutions for Type A behavior regressed on the predictor variables. As can be seen in Table X, maternal goal-setting and perceptions of goal attainment accounted for $22 \%$ of the variance in the Type A behavior of their daughters. These results indicate that mothers perceive their goals to be higher for daughters scoring high on Type A characteristics. They also indicated that the more Type A behavior their daughters displayed, the less likely their daughters were to attain these goals. While $22 \%$ of the variance was accounted for in daughters' Type A behavior, virtually none (7\%) of the variance was accounted for in the Type A behavior of their sons. Thus, mothers did not indicate that they set higher goals for their Type A sons than for their Type B sons, nor did they report that Type A sons differed in goal attainment from Type B sons. 7

As reported in Table XI, paternal educational aspirations and children's perceived knowledge of expectations accounted for $19 \%$ of the variance in the Type A behavior of daughters. These results indicate that the greater the degree of Type A behavior in their daughters, the more likely fathers were to have high educational aspirations for them. Additionally, fathers perceive that daughters with high Type A scores are aware of what is expected of them. 
As with mothers, a large percentage (19\%) of the variance was accounted for in daughters' Type A behavior, but only $8 \%$ of the variance was accounted for in the Type A behavior of sons. Fathers do not, therefore, report having higher educational aspirations for Type A sons than for Type B sons. Neither do fathers indicate that their Type A sons have greater knowledge of what is expected of them than their Type B sons.

In sum, the aspirations reported by parents in the present study were different for daughters and sons. Both mothers and fathers tended to report having higher aspirations for their Type A daughters than for their Type B daughters. In contrast, mothers and fathers alike did not report differences in their goal-setting behavior toward and expectations of Type $A$ and $B$ sons. 
TABLE X

MOTHERS' ASPIRATIONS AS PREDICTORS OF TYPE A BEHAVIOR IN CHILDREN

\section{Predictors}

Mothers' perceptions that they set higher goals for their children than other parents set for their offspring

Mothers' perceptions that their children attain the goals they set for them

$$
\begin{array}{r}
\text { Multiple } R \\
R^{2}
\end{array}
$$

Mothers' perceptions that they set higher goals for their children than other parents set for their offspring

Mothers' perceptions that their children attain the goals they set for them

$$
\begin{array}{rl}
\text { Multiple } \mathrm{R} & .26 \\
\mathrm{R}^{2} & .07
\end{array}
$$

Criteria

a) Daughters' Type A Behavior

$$
(N=17)
$$

$-.16$

.46

.22

b) Sons' Type A Behavior

$$
(\mathrm{N}=20)
$$


TABLE XI

FATHERS' ASPIRATIONS AS PREDICTORS OF TYPE A BEHAVIOR IN CHILDREN

Predictors

$$
\text { Criteria }
$$

a) Daughters' Type A Behavior

$$
(\mathrm{N}=12)
$$

Fathers' perceptions

that their children

know what is expected of them

Fathers's educational aspirations for their children

$$
\begin{array}{r}
\text { Mu1tip1e } R \\
\mathrm{R}^{2}
\end{array}
$$$$
.14
$$$$
.44
$$$$
.19
$$

b) Sons' Type A Behavior

$$
(\mathrm{N}=15)
$$

Fathers' perceptions

that their children

know what is expected of them

Fathers' educationa 1 aspirations for their children

$$
\begin{array}{rr}
\text { Multiple } R & .28 \\
\mathrm{R}^{2} & .08
\end{array}
$$


CHAPTER IV

DISCUSSION

\section{CHILDREN'S ASPIRATIONS AND PERFORMANCE}

The results of the present study indicate that Type A children do not set higher goals for themselves than Type B children. This result was unexpected, and contrasts previous research (Snow, 1978) which found Type A men to set higher goals for themselves than Type B men.

The discrepancy between Snow's results and the present findings may simply reflect an age difference in the samples. It may be that differences in goal-setting among Type As and Bs do not emerge during childhood. Recall that all children in the current study were preadolescents, while snow's subjects were between 17 and 58 years old.

Although Type As and Bs did not differ with respect to goal-setting, Type A females did perform at significantly higher levels than Type B females on the puzzles. The performance levels of male Type As and Bs did not differ, nor did Type A females outperform Type A males. These findings are consistent with snow's (1978) research which found no performance differences for Type $A$ and $B$ men on the same task.

Past research with both Type A adults (Burnam et al., 1975) and Type A male and female children (Matthews \& Volkin, 1981) has indicated that on tasks with explicit deadlines, performance differences do not exist between Type As and Bs. The finding in the present study that male Type A and B children did not differ in puzzle 
performance is therefore not surprising. It is unclear, however, why Type $B$ females performed poorly on the puzzles compared to Type A females and Type $A$ and $B$ males. One possible reason for the performance discrepancy concerns the fact that the Type $B$ females in the current study had very low Type $A$ and impatience-aggression (Factor 2) ratings when compared to the remaining three groups of children. Type $B$ females in this study had Type $A$ and Factor 2 scores not only lower than Type $A$ males and females, but also lower than most $(73 \%)$ of the Type $B$ males. Although not typically the case with deadiine tasks, the Type $B$ females in this sample might have been prone to work slower on the puzzles, thereby completing less of the puzzles in the allotted time period.

\section{PARENTAL ASPIRATIONS}

Parental responses to the questionnaire provide partial support for the notion that mothers and fathers set higher goals for their Type A daughters than for their Type $B$ daughters. Mothers perceive their goals to be higher for daughters scoring high on Type A characteristics. Further, mothers indicated that the more Type A behavior their daughters displayed, the less likely their daughters were to attain they goals they set for them. Fathers indicated that the greater the degree of Type A behavior in their daughers, the more likely they were to have higher educational aspirations for them. Additionally, fathers reported that daughers with high Type A scores are aware of what is expected of them.

Past research (Waldron et al., 1980) has reported that Type A women, compared to Type B women, recalled their mothers as having punished them more often physically. Research with mothers of Type A sons (Matthews et a1., 1977) has indicated that mothers tend to be critical of 
their child's performance and repeatedly push them to do better. Perhaps the present finding that mothers perceive their Type A daughers as not attaining the goals set for them reflects a tendency for mothers to be critical of their Type A daughters' performance. High goal-setting by mothers of Type As might also be related to a tendency to criticize their child's performance. Perhaps this reported high goal-setting by mothers of Type As is one way of trying to motivate their daughters to do better, and thus encourages Type A behavior.

In contrast to the responses of parents regarding their daughters, parents of sons did not indicate that they had higher aspirations for Type A sons than for Type B sons. Mothers of Type A sons did not report that they set higher goals for their sons than other mothers set for their children. Likewise, fathers of Type A sons, compared to fathers of Type B sons, did not report having higher educational aspirations for their sons.

The responses by parents of sons are somewhat surprising and difficult to explain. It is unclear why parents did not show a tendency toward higher aspirations for Type A sons than for Type B sons. Perhaps because parents who participated in the study were largely from middle- and upper-classes, the aspirations reported for their sons were similar, regardless of Type. Limited sample size might have also made it difficult to detect subtle differences in behavior toward Type A and B sons. In sum, the present study provides partial support for the notion that parents set higher aspirations for Type A daughters than for Type B daughters. No differences were noted for parents of Type $A$ and $B$ sons. The reasons differences were obtained for daughters but not for sons are perplexing. As noted above, it may be that these results are due in part to the nature of the sample. In addition to the socioeconomic status of most of the parents, several ( $19 \%)$ of the fathers who responded were 
raising their daughters as single parents. It may be that the parents who completed the questionnaire respond to their sons fairly similarly, but react to Type A (i.e., aggressive and competitive) daughters differently than to Type $B$ daughters.

\section{MEASUREMENT OF THE TYPE A BEHAVIOR PATTERN}

As indicated by the median Type A scores for boys and girls, the sample employed in this study was fairly similar to subject populations studied elsewhere. Previous studies (Iawler et a1., 1981; Matthews \& Angulo, 1980; Matthews \& Siegel, 1983; Matthews \& Volkin, 1981) have reported median MYTH Type A scores ranging from 51-54 for males and 45-51 for females. Thus, the Type A scores of the current sample were not atypical (however, Type B girls scored atypically low on Type A and impatience-aggression ratings).

It is interesting to note that, as with past research (Matthews \& Angulo, 1980), teachers assessed boys to be more Type A than girls. This finding is probably accounted for by the aggressive component of Type A behavior, and examination of Table I lends support to this idea. Observational studies of aggressive behavior (see Maccoby \& Jacklin, 1974 , 1980 for reviews) in boys and girls have noted a higher frequency of physically aggressive actions in males. Additionally, as Huston (in press) notes in her review of the literature on sex-typing, teachers, as well as other adults, perceive female students as having feminine characteristics and male students as having masculine characteristics. Since aggression is typically considered a "masculine" trait, teachers might perceive boys to be more aggressive than girls, even if they are not.

In contrast to the MYTH, no sex differences emerged when the Hunter-Wolf was used to classify children by Type. This result is also consistent with past research 
(Wolf et al., 1982) which reported no sex differences in self-ratings of Type A behavior. Thus, sex differences in Type A behavior are only noted when the behavior pattern is assessed by an external observer.

Another explanation for the above results on sex differences, which may not be incompatible with the ideas already mentioned, concerns the fact that the reference points of individuals completing the assessment instruments are different. Recall that teachers generally complete the MYTH and children complete the Hunter-Wolf themselves. Because teachers are asked to rate children's behavior in terms of how they relate to others (e.g., when playing games, when working with others, when competing), children are compared to one another and the point of reference becomes the group the children are in. This is not true of the Hunter-Wolf. There are two questions about a child's relationship to his or her peers (in leadership roles), but the remainder of the instrument focuses on how the child perceives herself to be, and does not use the context of a group. Consequently, a child is not asked to compare herself to others. A child does not have to decide, for example, if she argues more than John or sue, but only if she likes to argue.

Also, children's perceptions of their behavior might wel1 differ from others' perceptions of their behavior, resulting in the lack of sex differnces using the HunterWolf. Although research has shown that Type A adults are able to accurately describe themselves using a self-rating instrument (Herman, Blumenthal, Black, \& Chesney, 1981), children might not be old enough to accurately perceive their behavior. Boys, for example, might perceive themselves to be less aggressive or competitive than others perceive them to be.

Regarding the correspondence of MYTH Type A ratings and the Hunter-Wolf Type A ratings, the correlation 
between these two instruments was marginally significant for both sexes combined, but was not significant when correlations were examined separately for each sex. There are several possible explanations for this finding. As mentioned above, the fact that one instrument employs others' ratings of behavior and relies on intragroup comparisons, and a second uses self-ratings of behavior, thereby creating a different point of reference, may account for the relative lack of correspondence. Second, it may be that the Hunter-Wolf Rating Scale assesses only a part of the Type A behavior pattern. While the HunterWolf has been found to be a reliable instrument (see the Method section), the validation study (Wolf et al., 1982) provided only partial support for its validity. The MYTH, by contrast, has been found to be both a reliable and a highly valid instrument. Assuming the Hunter-Wolf does assess part of the Type A behavior pattern, this accounts for the marginally significant relationship between the Type A ratings of the MYTH and the Hunter-Wolf. To conclude, it appears that the MYTH and the HunterWolf Rating Scale may be assessing different aspects of Type A behavior in children. Several issues involving these assessment instruments need to be explored. These include teachers' biases in rating Type A behavior, problems of self-perception in completing the Hunter-Wolf, and the stability of the Hunter-Wolf over time.

\section{SUMMARY AND SUGGESTIONS FOR FUTURE RESEARCH}

The present study examined goal-setting behaviors displayed by Type $A$ and $B$ children, parents' goal-setting behaviors toward their offspring, and aspects of assessment of the Type A behavior pattern.

With respect to goal-setting, Type A children in this study did not set higher goals for themselves than Type $B$ 
children. This result may have been due to the age of the children. It is possible that the differences in goal-setting between Type As and Bs emerge during adolescence. Crosssectional and/or longitudinal studies of goal-setting need to be conducted to determine at what age these differences become evident.

An assessment of parental aspirations generally indicated that parents set higher goals for their Type A daughters than for their Type B daughters. No differences were noted between parents of Type A and B sons. The lack of differences between parents of Type A and $B$ sons could be due to the characteristics of this sample and the limited responses from fathers. Future research on parental aspirations needs to include more representative samples. Additionally, alternative measures of parental goal-setting which have established criterion validity should be employed. Rather than relying entirely on self-report data, future studies of parental aspirations should incorporate observations of parent-child interactions in naturalistic environments.

Finally, a comparison of the two most common instruments used to assess Type A behavior in children revealed that they correlated only marginally. This result may be due to biased ratings by teachers in completing the MYTH, problems of self-perception in completing the Hunter-Wolf Rating Scale, or only partial validity of the Hunter-Wolf. Future research needs to focus on the stability and validity of the Hunter-Wolf in assessing Type A behavior. Researchers also need to explore the problems of biases by self and others in rating Type A behavior. 
American Psychological Association. (1981). Ethical principles of psychologists. Washington, D. C.:

American Psychological Association.

Berenson, G., McMahan, C., Voors, A., Webber, L., Srinivasan, S., Frank, G., Foster, T., \& Blonde, C. (1980). Cardiovascular risk factors in children--the early natural history of atherosclerosis and essential hypertension. New York: Oxford University Press.

Bernstein, M. E. (1975). A developmenta1 study of the influence which approval and disapproval reactions of others exert upon the level-of-aspiration and physical self-concept in kindergarten, second, and fourth grade boys (Doctoral dissertation, Pennsylvania State University, 1974). Dissertation Abstracts Internationa 1 35 (11-A), 7115-A.

Blumentha1, J. A., Williams, R., Kong, Y., Schanberg, S. M., \& Thompson, L. W. (1978). Type A behavior and angiographically documented coronary disease. Circulation, 58, 634-639.

Bortner, R. W., \& Rosenman, R. H. (1967). The measurement of Pattern A behavior. Journal of Chronic Diseases, 20, 525-533.

Bortner, R. W., Rosenman, R. H., \& Friedman, M. (1970). Familial similarity in Pattern A behavior. Journal of Chronic Diseases, $23,39-43$.

Brunson, I., \& Matthews, K. A. (1981). The Type A coronary-prone behavior pattern and reactions to uncontrollable events: An analysis of learned helplessness. Journal of Personality and Social Psychology, 40, 906-918.

Buck, C., \& Stenn, P. G. (1979). Personality factors and blood pressure in children. Journal of Psychosomatic Research, 23, 13-15. 
Burnam, M. A., Pennebaker, J. W., \& Glass, D. C. (1975).

Time consciousness, achievement-striving, and the Type

A coronary-prone behavior pattern. Journal of Abnormal

Psychology, 84, 76-79.

Butensky, A., Faral1i, V., Heebner, D., \& Wa1dron, I. (1976).

Elements of the coronary-prone behavior pattern in

children and teen-agers. Journal of Psychosomatic

Research, 20, 439-444.

Carver, C. S., Coleman, A. E., \& Glass, D. C. (1976).

The coronary-prone behavior pattern and suppression of

fatigue on a treadmill test. Journal of Personality and

Socia1 Psychology, 36, 460-466.

Carver, C. S., \& Glass, D. C. (1978). Coronary-prone

behavior pattern and interpersonal aggression. Journal

of Personality and Social Psychology, 36, 361-366.

Contrada, R. J., Glass, D. C., Krakoff, L. R., Krantz,

D. S., Kehoe, K., Isecke, W., Collins, C., \& E1ting,

E. (1982). Effects of control over aversive stimulation

and Type A behavior on cardiovascular and plasma

catecholaminic responses. Psychophysiology, 19(4), 408-419.

Dembroski, T. M., MacDouga11, J. M., Herd, J. A., \& Shields, J. L. (1979). Effects of level of challenge on pressor and heart responses in Type $A$ and $B$ subjects. Journal of Applied Social Psychology, 9, 209-228.

Dembroski, T. M., MacDouga11, J. M., \& Lushene, R. (1979).

Interpersonal interaction and cardiovascular response in Type A subjects and coronary patients. Journal of Human Stress, $5(4), 28-36$.

Dembroski, T. M., MacDouga11, J. M., Shields, J. L.,

Petito, J., \& Lushene, R. (1978). Components of the

Type A coronary-prone behavior pattern and cardiovascular responses to psychomotor performance challenge.

Journa1 of Behavioral Medicine, 1, 159-176. 
Friedman, M., \& Rosenman, R. H. (1974). Type A behavior and your heart. New York: Knopf.

Glass, D. C. (1977). Behavior patterns, stress, and coronary disease. Hillsdale, New Jersey: Lawrence Erlbaum Associates, Inc.

Glass, D. C., Krakoff, L. R., Contrada, R., Hilton, W. F., Kehoe, K., Mannucci, E. G., Collins, C., Snow, B., \& Elting, E. (1980). Effect of harassment and competition upon cardiovascular and catecholaminic responses in Type A and B individuals. Basic and Applied Social Psychology, 1, 199-218.

Glass, D. C., Snyder, M. L., \& Hollis, J. F. (1974). Time urgency and the Type A coronary-prone behavior pattern. Journal of Applied Social Psychology, 4 , 125-140.

Huston, A. C. (in press). Sex-typing. In E. M. Heatherington (Ed.), Handbook of child psychology: Vol. 4. Socialization, personality, and social development (4th ed.). New York: Wiley. Insel, P. M., Fraser, G. E., Phillips, R., \&Williams, P. (1981). Psychosocial factors and blood pressure in children. Journal of Psychosomatic Research, 25, 505-511.

Herman, S., Blumenthal, J. A., Black, G. A., \& Chesney, M. A. (1981). Self-ratings of Type A (coronary-prone) adults: Do Type A's know they are Type A's? Psychosomatic Medicine, 43(5), 405-413. Jenkins, C. D. (1976). Recent evidence supporting psychologic and social risk factors for coronary disease. New Engla nd Journal of Medicine, 294, 1033-1038. Jenkins, C. D., Rosenman, R. H., \& Friedman, M. (1967). Development of an objective psychological test for the determination of the coronary-prone behavior pattern in employed men. Journal of Chronic Diseases, 20 , $371-379$. 
Jenkins, C. D., Rosenman, R. H., \& Friedman, M. (1968).

Replicability of rating the coronary-prone behavior pattern. British Journal of Preventive and Social Medicine, 22, 16-22.

Jenkins, C. D., Rosenman, R. H., \& Zyzanski, S. J. (1974). Prediction of clinical coronary heart disease by a test for the coronary-prone behavior pattern. New England Journal of Medicine, 290, 1271-1275.

Jenkins, C. D., Zyzanski, S. J., \&Rosenman, R. H. (1971). Progress toward validation of a computer-scored test for the Type A coronary-prone behavior pattern. Psychosomatic Medicine, 33, 193-202.

Krantz, D. S., Shaeffer, M. A., Davia, J. E., Dembroski, T. M., MacDouga11, J. M., \& Shaffer, R. T. (1981). Extent of coronary atherosclerosis, Type A behavior, and cardiovascular response to social interaction. Psychophysiology, 18, 654-664.

Lawler, K. A., \&Allen, M. T. (1981). Risk factors for hypertension in children: Their relationship to psychophysiological responses. Journal of Psychosomatic Research, 25, 199-204.

Lawler, K. A., Allen, M. T., Critcher, E. C., \& Standard, B. A. (1981). The relationship of physiological responses to the coronary-prone behavior pattern in children. Journal of Behavioral Medicine, 4 (2), 203-216.

Lova110, W. R., \& Pishkin, V. (1980). A psychophysiological comparison of Type $A$ and $B$ men exposed to failure and uncontrollable noise. Psychophysiology, 17, 29-36. Lundberg, U. (1983). Note on Type A behavior and cardiovascular responses to challenge in 3-6 year old children. Journal of Psychosomatic Research, 27(I), 39-42.

Lundberg, P. K., Warm, J. S., Seeman, W., \& Porter, P. K. (1980). Vigilance and the Type A individual: Attentive, 
aroused, able. Paper presented at the meeting of the Midwestern Psychological Association, Chicago, IL. Maccoby, E. E., \& Jacklin, C. N. (1974). The psychology of sex differences. Stanford, California: Stanford University Press.

Maccoby, E. E., \& Jacklin, C. N. (1980). Sex differences in aggression: $A$ rejoinder and reprise. Child Development, 51, 964-980. Manuck, S. B., Craft, S. A., \& Gold, K. J. (1978). Coronary-prone behavior pattern and cardiovascular response. Psychophysiology, 15, 403-411.

Manuck, S. B., \& Garland, F. N. (1979). Coronary-prone behavior pattern, task incentive, and cardiovascular respónse. Psychophysiology, 16, 139-142.

Matthews, K. A. (1979). Efforts to control by children and adults with the Type A coronary-prone behavior pattern. Child Development, 50, 842-847.

Matthews, K. A. (1981). Antecedents of the Type A coronary-prone behavior pattern. In S. S. Brehm, S. M. Kassin, \& F. X. Gibbons (Eds.). Developmental social psychology (pp. 235-248). New York: Oxford University Press.

Matthews, K. A. (1982). Psychological perspectives on the Type A behavior pattern. Psychological Bulletin, $91(2)$, 293-323.

Matthews, K. A., \&Angu1o, J. (1980). Measurement of the Type A behavior pattern in children: Assessment of children's competitiveness, impatience-anger, and aggression. Child Development, 51, 466-475.

Matthews, K. A., \& Avis, N. E. (in press). Stability of overt Type A behaviors in children: Results from a one year longitudinal study. Child Development.

Matthews, K. A, \& Brunson, B. I. (1979). Allocation of attention and the Type A coronary-prone behavior pattern. Journal of Personality and Social Psychology, 37 , 
$2081-2090$.

Matthews, K. A., Glass, C. D., \& Richins, M. (1977). The mother-sòn observation study. In D. C. Glass, Behavior patterns, stress, and coronary disease. Hillsdale, New Jersey: Lawrence Erlbaum Associates, Inc.

Matthews, K. A., Helmreich, R. L., Beane, W. E., \& Lucker, G. W. (1980). Pattern A, achievement-striving, and scientific merit: Does Pattern A help or hinder? Journal of Personality and Social Psychology, 39 , 962-967.

Matthews, K. A., \& Krantz, D. S. (1976). Resemblance of twins and their parents in Pattern A behavior. Psychosomatic Medicine, 38, 140-144. Matthews, K. A., \& Siege1, J. M. (1983). Type A behaviors by children, social comparison, and standards for selfevaluation. Developmenta1 Psychology, 19(1), 135-140. Matthews, K. A., \& Volkin, J. I. (1981). Efforts to excel and the Type A behavior pattern in children. Child Development, 52, 1283-1289.

Ovcharchyn, C. A., Johnson, H. H., \& Petze1, T. P. (1981). Type A behavior, academic aspirations, and academic success. Journal of Personality, 49, 249-256. Raynor, J. 0., \& Smith, C. P, (1966). Achievement related motives and risk taking in games of skill and chance. Journal of Personality, 34, 176-198.

Rosenman, R. H. (1978). The interview method of assessment of the coronary-prone behavior pattern. In T. M. Dembroski, S. M. Weiss, J. L. Shields, S. G. Haynes, \& M. Feinleib (Eds.), Coronary-prone behavior. New York: Springer-Verlag, 1978 . Rosenman, R. H., Brand, R. J., Jenkins, C. D., Friedman, M., Straus, R., \&Wurm, M. (1975). Coronary heart disease in the Western Collaborative Group Study: Final follow up experience of $8 \frac{1}{2}$ years. Journal of the 
American Medical Association, 233, 872-877.

Rosenman, R. H., Friedman, M., Straus, R., Wurm, M.,

Kositchek, R., Hahn, W., \& Werthessen, N. T. (1964).

A predictive study of coronary heart disease. Journal

of the American Medical Association, 189, 103-110.

Scherwitz, L., Berton, K., \& Leventhal; H. (1978). Type

A behavior, self-involvement, and cardiovascular

response. Psychosomatic Medicine, 40, 593-609.

Sears, P. S. (1940). Level of aspiration in academica11y

successful and unsuccessful children. Journal of

Abnormal and Social Psychology, 35, 498-536.

Siege1, J. M., Matthews, K. A., \& Leitch, C. J. (1981).

Validation of the Type $A$ interview assessment of

adolescents: A multidimensional approach. Psychosomatic

Medicine, 46, 311-321.

Snow, B. (1978). Level of aspiration in coronary and

noncoronary prone adults. Personality and social

Psychology Bulletin, 4 (3), 416-419.

Strong, J., \& McGil1, H. (1969). The pediatric aspects

of atherosclerosis. Journal of Atherosclerosis Research,

9, 251-265.

Waldron, I., Hickey, A., McPherson, C., Butensky, A.,

Gruss, L., Overa11, K., Schmader, A., \& Wohlmuth, D.

(1980). Type A behavior pattern; Relationship to

variation in blood pressure, parental characteristics,

and academic and social activities of students. Journal

of Human Stress, 6 , 16-27.

Weidner, G., \& Matthews, K. A. (1978). Reported physical

symptoms elicited by unpredictable events and the Type

A coronary-prone behavior pattern. Journal of Personality

and Social Psychology, 36, 1213-1220.

Wolf, T. M., Hunter, S. M., Webber, L. S., \& Berenson, G. S.

(1981). Self-concept, locus of control, goal blockage, and coronary-prone behavior in children and adolescents:

Bogalusa heart study. Journal of General Psychology, 
105, 13-26.

Wolf, T. M., Sklov, M. C., Wenzl, P. A., Hunter, S. M., \& Berenson, G. S. (1982). Validation of a measure of Ty-pe A behavior pattern in children: Bogalusa heart study. Child Development, 53, 126-135. 
FOOTNOTES

${ }^{1}$ Completed data were obtained on 64 children. Sixteen were from single-parent homes. A total of 60 mothers and 51 fathers were available to participate, accounting for the discrepancy in the percentage of response rates for mothers and fathers.

2 Median splits were used to classify the children by Type, and were calculated separately for males (MD $=55.00$ on the MYTH, 94.50 on the Hunter-Wolf) and females (MD = 43.83 on the MYTH, 92.50 on the Hunter-Wolf).

${ }^{3}$ When classified by the Hunter-Wolf, male Type As performed at significantly higher levels than male Type Bs on puzzle 5 and on mean puzzle performance ts (29) $\geq 4.15$, ps $<.05$. Type As performed at marginal1y significant higher levels than Type Bs on puzzles 2 and 4 , ts $(29) \geq 3.30$, ps $<.08$.

${ }^{4}$ When classified by the Hunter-Wolf, female Type As outperformed female Type Bs only on puzzle $3, \underline{t}(33)=3.31$, $\underline{\mathrm{p}}<.08$.

${ }^{5}$ Bivariate correlations between Hunter-Wolf Type A scores and parental questionnaire responses differed widely from correlations obtained using the MYTH to assess Type A behavior. Significant correlations were obtained on two responses by fathers. Question 3 (value of goal-setting generally) was positively correlated with Type A behavior $(\underline{r}=.39, \underline{p}<.05)$, and Question 5 (educational aspirations) correlated negatively $(\underline{\mathrm{r}}=-.53, \underline{\mathrm{p}}<.005)$ with Type A behavior.

${ }^{6}$ Due to the small sample size, only two predictors were used in each of the four regression analyses.

7 In addition to the regression analyses, a series of 2 (sex of child) $x 2$ (Type of child) ANovAs were performed 
to assess parental aspirations. Mothers of Type A children (relative to mothers of Type $B$ children) reported that they set higher goals for their children than other parents $(\underline{F}(3, .33)=2.86, \underline{p}<.05$, one-tailed). 
APPENDIX A

INFORMED CONSENTS 
I, hereby agree to

serve as a subject in the research project on personality and goals conducted by Wendy kliewer under the supervision of Dr. Gerdi Weidner.

I understand that the study involves

(1) completing a short (24-item) Health Habits Questionnaire on my personal likes and dislikes, habits, and behavior, and

(2) working 5 "Connect the Numbers" puzzles.

I understand that before I begin each puzzle I will be asked how far I will try to get in the puzzle during a minute.

I understand that this study will take about 45 minutes of my time, and that some of the information I give will be private. I also understand that no one except the investigator will see my scores on the puzzles and Health Habits Questionnaire. All information will be kept strictly confidentia1.

It has been explained to me that the purpose of this study is to learn how different boys and girls solve these puzzles.

Wendy Kliewer has offered to answer any questions I may have about the study.

I understand that I do not have to participate in the study if I choose not to, and that if I decide not to participate my grades in this school will not be affected.

I have read and understand the above information. Date Signature 
I, hereby agree to serve

as a subject in the research project on personality and goals conducted by Wendy kliewer under the supervision of Dr. Gerdi Weidner. I also agree to allow my child to participate in this research.

I understand that my involvement in this research is simply completing a short questionnaire regarding the goals $I$ set for my child. I understand that my child's involvement includes completing a short Health Habits Questionniare and working 5 "Connect the Numbers" puzzles.

I understand that my participation will take approximatley 15 minutes of my time. I also understand that no one except the investigator will see my questionniare responses and my child's responses to the questionnaire and puzzles. All information will be kept strictly confidential, and the identity of all participants in this research project will remain anonymous.

It has been explained to me that the purpose of this study is to research individual differences in the way people set goals and their performance on tasks. I understand that the results of the study will be made available to me, if $I$ so desire, once the research is complete.

I may not receive any direct benefit from participation in this study, but my participation may help to increase knowledge which may benefit others in the future.

Dr. Gerdi Weidner has offered to answer any questions I may have about the study, and may be contacted at the oregon Health Sciences University, 225-8005. 
I understand that $I$ am free to withdraw from participation in this study at any time without jeopardizing my relationship with Portland State University and/or Cathedral School.

I have read and understand the foregoing information.

Date Signature

If you experience problems that are the result of your participation in this study, please contact John Lorentz, Office of Graduate Studies and Research, 105 Neuberger Ha11, Portland State University, 229-3423. 
I, hereby agree to assist in the research project on personality and goals conducted by Wendy. Kliewer under the supervision of Dr. Gerdi Weidner.

I understand that my involvement in the study includes completing a 17-item questionnaire on each of my students in which I rate statements on a 5-point scale as being characteristic or uncharacteristic of a student.

I understand the study will take approximately 60 minutes of my time and 45 minutes of classroom time. To protect privacy, I understand that no one except the investigator will see my student ratings. All information will be kept strictly confidential, and the identity of all participants in this research will remain anonymous.

It has been explained to me that the purpose of this study is to research individual differences in goal-setting and performance. I understand that the results of this study will be made available to me, if I so desire, once the research is complete.

I may not receive any direct benefit from participation in this study, but my participation may help to increase knowledge which may benefit others in the future.

Dr. Gerdi Weidner has offered to answer any questions I may have about the study, and may be contacted at the Oregon Health Sciences University, 225-8005.

I understand that $I$ am free to withdraw from participation in this study at any time without jeopardizing my relationship with Portland State University and/or Cathedral School. 
I have read and understand the foregoing information.

Date Signature

If you experience any problems that are the result of your participation in this study, please contact John Lorentz, Office of Graduate Studies and Research, 105 Neuberger Ha11, Portland State University, 229-3943. 
APPENDIX B

MEASURES USED TO ASSESS TYPE A BEHAVIOR 
The Matthews Youth Test for Health

Name of Child

Age

Rater

This rating scale is designed to assess various aspects of a child's behavior. Please mark how well the statement characterizes the child using the following scale:
1
2
3
4
5

extremely uncharacteristic neutral characteristic extremely unchar-

acteristic

characteristic

1. When this child plays games, he/she is competitive.
1
2
3
4
5

2. This child works quickly and energetically rather than slowly and deliberately.
1
2
3
4
5

3. When this child has to wait for others, he/she becomes impatient.
1
2
3
4
5

4. This child does things in a hurry.

1

2

3

4

5

5. It takes a lot before this child gets angry at his/her peers.
1
2
3
4
5

6. This child interrupts others.

1

2

3

4

5

7. This child is a leader in various activities.

1

2

3

4

5

8. This child gets irritated easily. 
1

$$
2
$$

extremely uncharacteristic uncharact-

eristic
3

neutral

characteristic
extremely character- istic

9. He/she seems to perform better than usual when competing against others.
1
2
3
4
5

10. This child likes to argue or debate.
1
2
3
4
5

11. This child is patient when working with children slower than he/she is.
1
2
3
4
5

12. When working or playing, he/she tries to do better than other children.
1
2
3
4
5

13. This child can sit still long.
1
2
3
4
5

14. It is important to this child to win, rather than to have fun in games or schoolwork.
1
2
3
4
5

15. Other children look to this child for leadership.
1
2
3
4
5

16. This child is competitive.
1
2
3
4
5

17. This child tends to get into fights.

1

2

3

4

5

Thank you. 
HEALTH HABITS QUESTIONNAIRE

\section{EXAMPLE}

INSTRUCTIONS: Here is a picture of a ladder. At the bottom is a statement: I am very hungry. At the top is a statement: I am not very hungry. Which statement is more like you? of course, you may be somewhere in between. Put an " $X$ " on the step where you are on this ladder most of the time.

I am not very hungry.

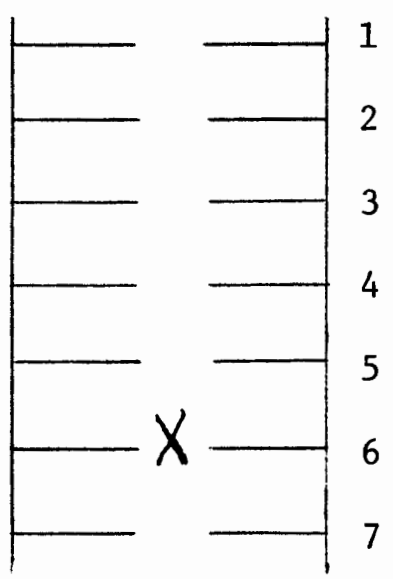

If you think you are hungry much of the time, but not all of the time, you would put an "X" here.

I am very hungry.

BE SURE YOU ANSWER THE QUESTIONS IN THE NUMBERED ORDER. ALL OF YOUR ANSWERS WILL BE KEPT SECRET. 
1. I am easy going. 2. I feel time passes 3. I walk fast.

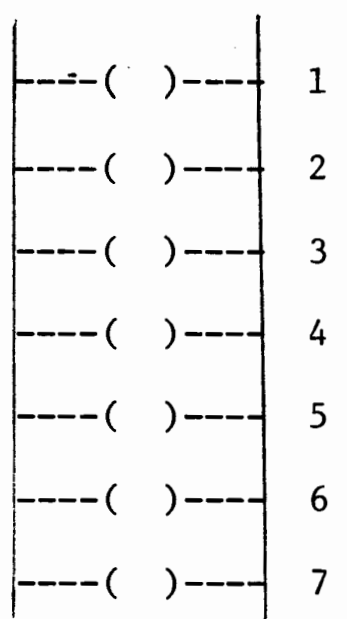

I am hard driving. quickly.

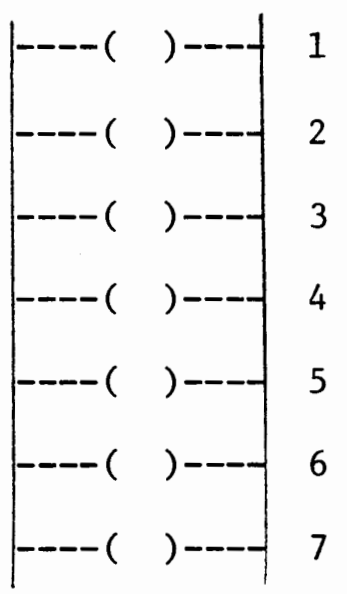

I feel time passes slowly.

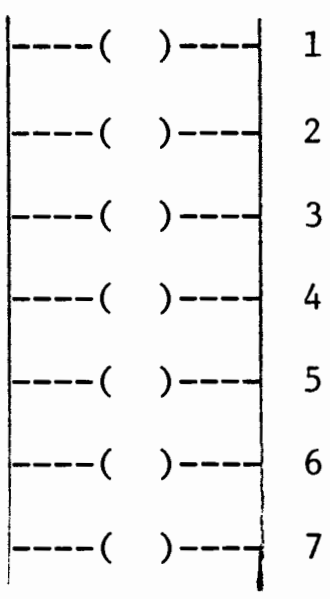

I walk slowly.
4. I take it easy and put little effort into the things I do.

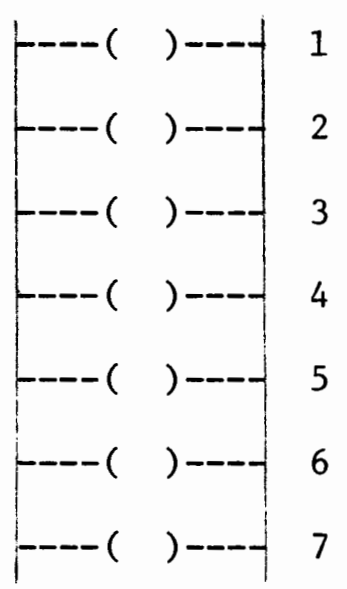

I go al1 out and put a lot of effort into the things I do.
5. It does matter if I am late.

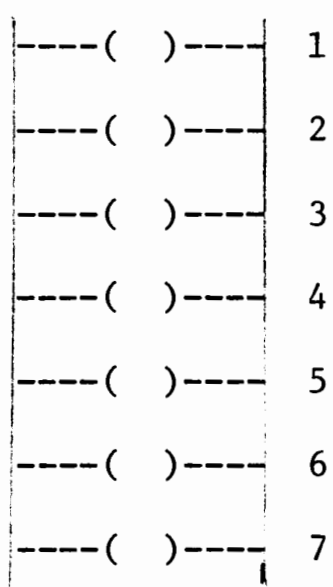

It doesn't matter if I am late.
6. I always want to win at everything.

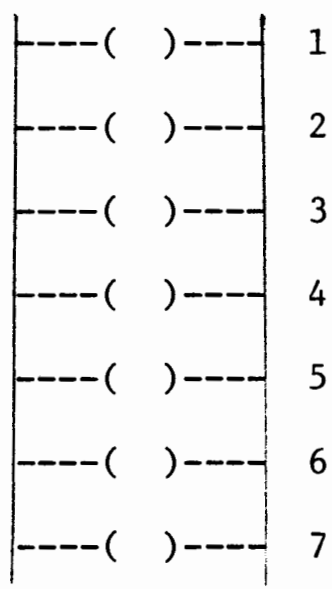

I don't care if I win at anything. 

7. I often break in or else is talking.

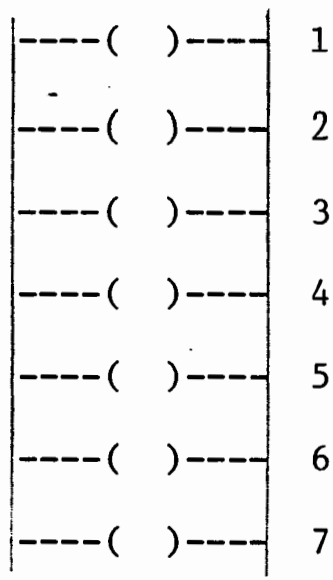

I always sit and listen when someone else is talking.
8. I have no interests.

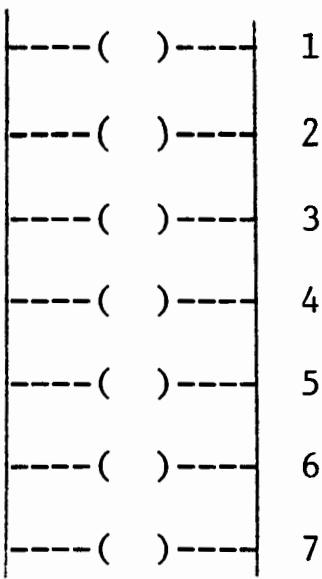

I have many interests.
9. I want to do better in school.

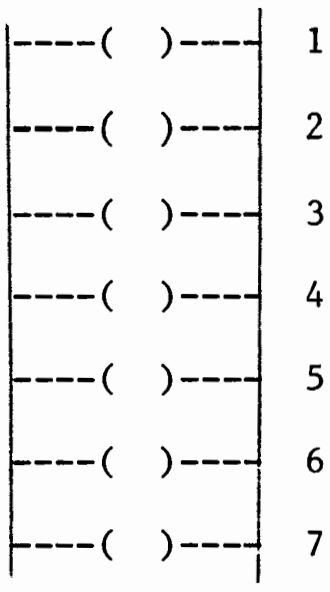

I am satisfied with how well I am doing in school.
10. I find it difficult 11. I talk slowly: to wait.

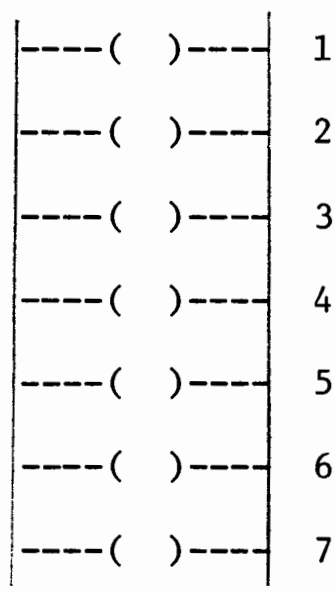

I find it easy to wait.

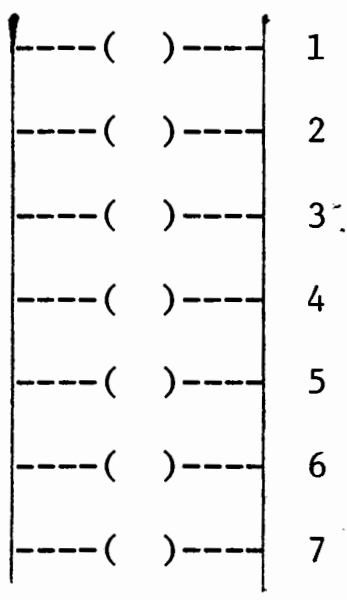

I talk fast.
12. I talk loud.

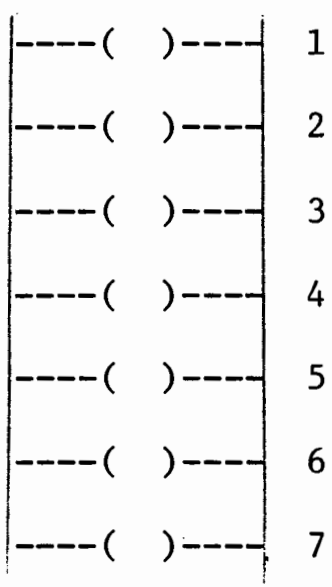

I talk softly.

GO TO NEXT PAGE 
13. I always feel rushed. 14. I eat slowly.

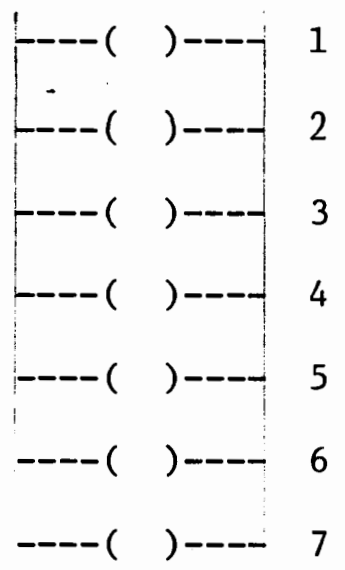

I never feel rushed.

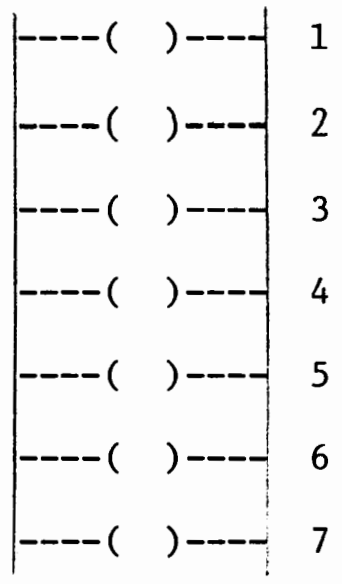

I eat fast.
15. I think about many things at the same time.

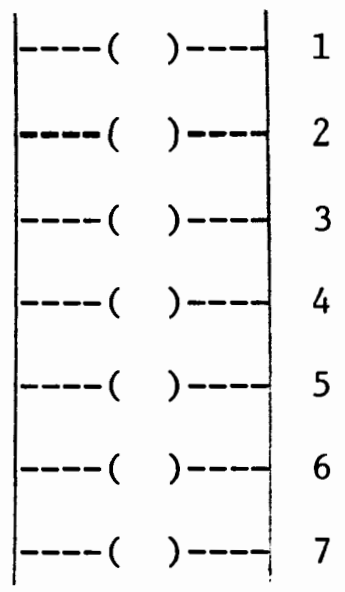

I think about one thing at a time.
16. I like to argue.

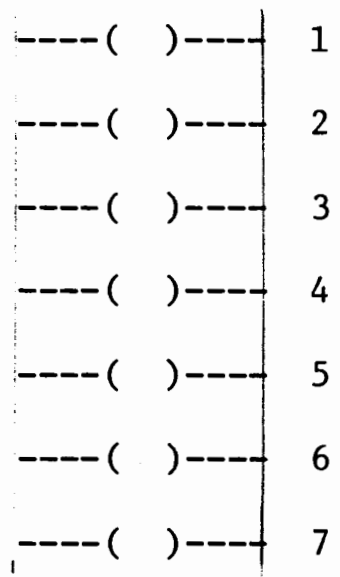

I don't like to argue.
17. I often get into fights.

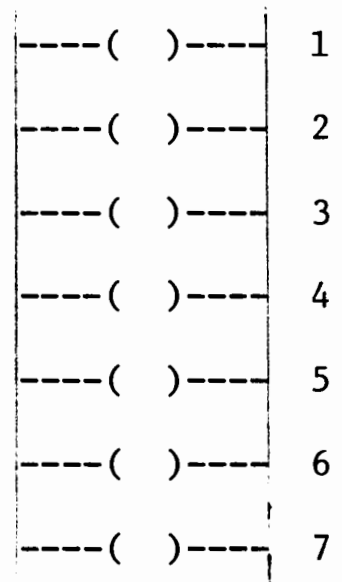

I never get into fights.
18. I like to tell others what to do.

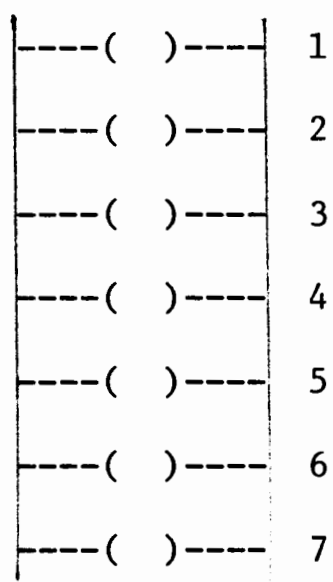

I don't like to tell others what to do. 
19. It takes a lot to get me angry.

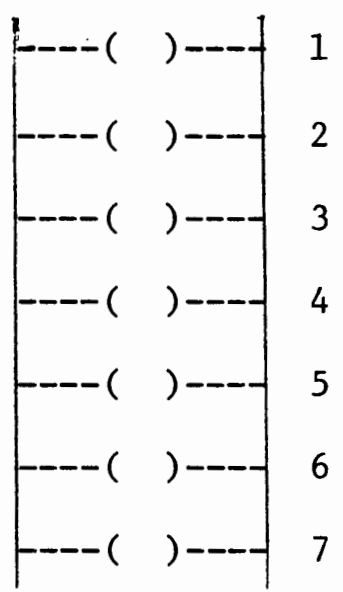

It takes very little to get me angry.
20. I am always a leader in activities

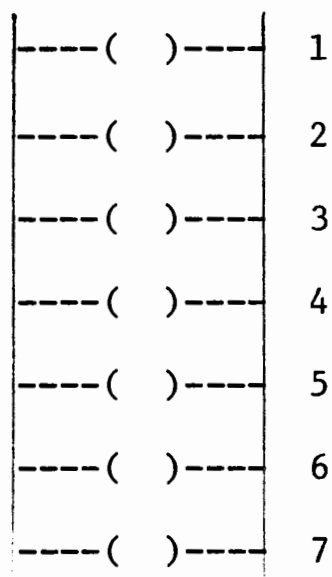

I am never a leader in activities.
21. My friends always pick me to be leader when we play games.

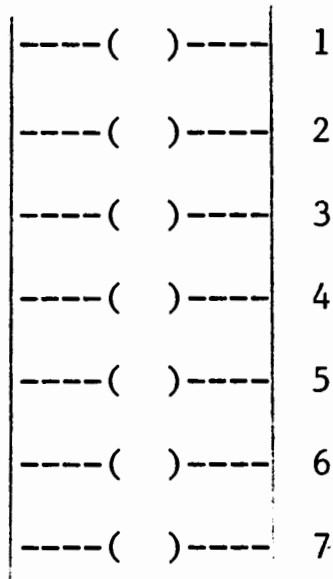

My friends never pick me to be leader when we play games.
22. I drink fast.

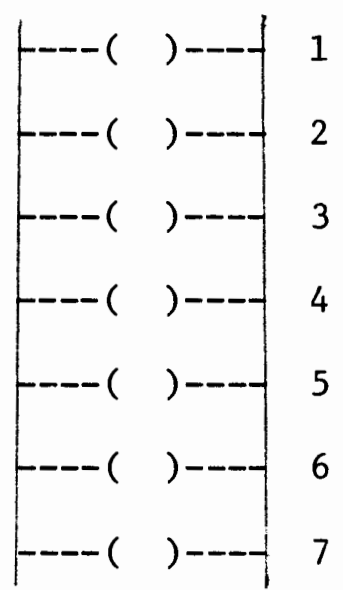

I drink slowly.
23. I have many hobbies. 24. I lose my temper easily.
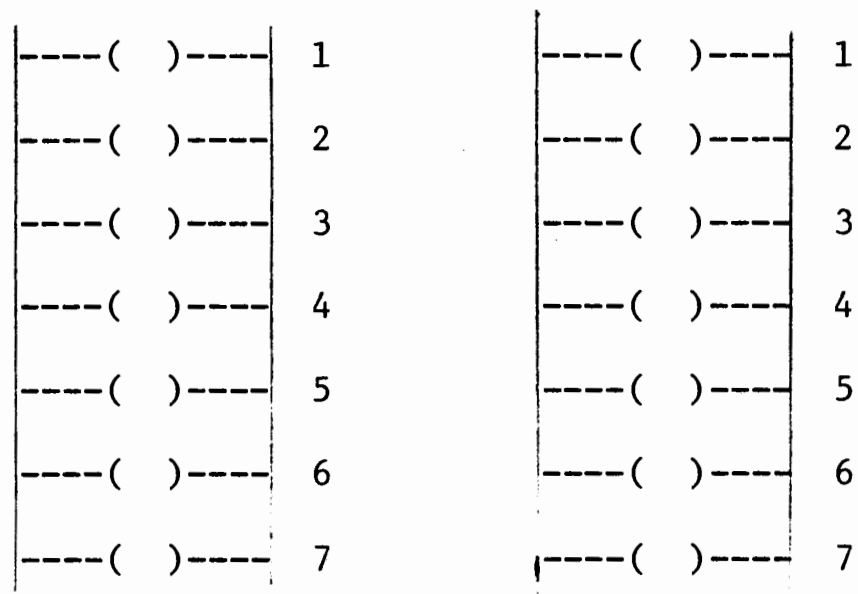

I have few hobbies.
I do not lose my temper easily. 


\section{APPENDIX C}

MEASURES USED TO ASSESS ASPIRATIONS 
This booklet contains five puzzles. For each puzzle your task is to draw a line connecting the numbers in order from 1 to the last number. Follow the line in the example below. The line connects the numbers in order going from 1 , marked $\mathrm{S}$ for START, to 2 , then to 3 , then to 4 , and so on to 11 , the last number, marked F for FINISH.

\section{$\underline{\text { Examp } 1 \mathrm{e} 1}$}

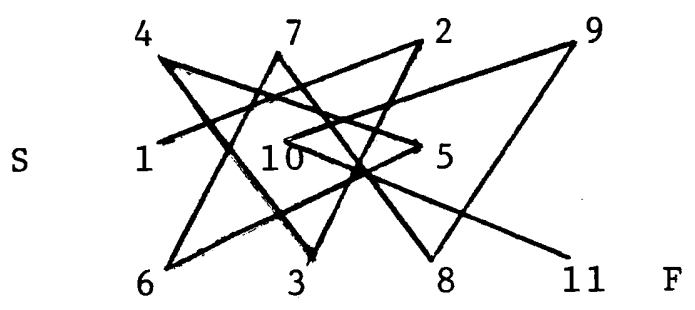

Now you try the next example. Draw an unbroken line from $S$ to $F$ connecting the numbers in order from 1 to 13.

\section{Work This Example}

$\begin{array}{rrrr} & 9 & 7 & 5 \\ & 8 & 10 & 6 \\ \text { F } 13 & 11 & 4 & 2 \\ & 12 & 1 & 3 \\ & & \text { s } & \end{array}$

The last number in each of the puzzles in this booklet is 80. However, you may not get that far in the one minute which will be allowed for each puzzle. 
PUZZLE 1

Write the number you will try to reach in one minute.

24

$\begin{array}{llllllll}23 & 20 & 26 & 31 & 28 & 77 & 74 & 69\end{array}$

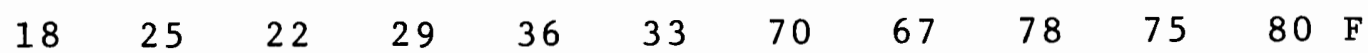

$\begin{array}{llllllllll}21 & 13 & 19 & 32 & 27 & 30 & 35 & 76 & 73 & 68\end{array}$

$\begin{array}{llllllllll}14 & 17 & 11 & 37 & 34 & 71 & 66 & 63 & 60 & 79\end{array}$

$\begin{array}{llllllll}12 & 10 & 16 & 41 & 38 & 61 & 72 & 65\end{array}$

$\begin{array}{lllllllll}6 & 15 & 8 & 39 & 46 & 43 & 64 & 59 & 62\end{array}$

$\begin{array}{lllllllll}9 & 2 & 5 & 42 & 49 & 40 & 45 & 56 & 53\end{array}$

$\begin{array}{lllllll}4 & 7 & 47 & 44 & 51 & 54 & 58\end{array}$

$\begin{array}{lllllll}\mathrm{S} 1 & 3 & 50 & 48 & 57 & 52 & 55\end{array}$ 
PUZZLE 2

Write the number you will try to reach in one minute.

$28 \quad 31 \quad 42$

$\begin{array}{lllllll}27 & 30 & 33 & 36 & 39 & 46 & 41\end{array}$

$\begin{array}{lllllll}35 & 26 & 29 & 32 & 43 & 38 & 45\end{array}$

$\begin{array}{llllllll}25 & 22 & 19 & 34 & 37 & 40 & 47 & 56\end{array}$

$\begin{array}{llllllll}14 & 17 & 24 & 21 & 48 & 53 & 44 & 51\end{array}$

$\begin{array}{llllllll}23 & 20 & 15 & 18 & 50 & 55 & 60 & 57\end{array}$

$\begin{array}{lllllllll}16 & 13 & 10 & 49 & 54 & 59 & 52 & 65 & 62\end{array}$

$\begin{array}{llllllll}3 & 8 & 5 & 12 & 67 & 64 & 61 & 58\end{array}$

$\begin{array}{lllllllll}6 & 11 & 2 & 9 & 72 & 75 & 66 & 63 & 70\end{array}$

$\begin{array}{lllllllll}\mathrm{S} & 1 & 4 & 7 & 76 & 79 & 68 & 71 & 74\end{array}$

77

$73 \quad 80 \quad 69$

F 
PUZZLE 3

Write the number you will try to reach in one minute.

$58 \quad 63 \quad 61$

54

$56 \quad 59 \quad 64$

67

69

78

$\begin{array}{llll}57 & 46 & 53 & 62\end{array}$

$60 \quad 65$

$77 \quad 70$

$\begin{array}{llllllllll}52 & 55 & 50 & 45 & 66 & 33 & 68 & 71 & 79 & 73\end{array}$

$\begin{array}{llllllllll}51 & 48 & 37 & 32 & 41 & 34 & 29 & 72 & 80 & \text { F }\end{array}$

$\begin{array}{llllllll}38 & 43 & 40 & 35 & 30 & 26 & 75 & 28\end{array}$

$\begin{array}{lllllllll}3 & 8 & 5 & 14 & 11 & 20 & 23 & 16 & 25\end{array}$

$\begin{array}{llllllll}6 & 13 & 2 & 9 & 22 & 15 & 18 & 27\end{array}$

$\begin{array}{llllllllll}\mathrm{S} & 1 & 4 & 7 & 12 & 19 & 10 & 21 & 24 & 17\end{array}$ 
PUZZLE 4

Write the number you will try to reach in one minute.

\begin{tabular}{|c|c|c|c|c|c|c|c|c|c|c|}
\hline \multirow{3}{*}{21} & & \multicolumn{9}{|c|}{$S$} \\
\hline & 24 & 17 & 14 & 19 & 12 & 1 & 4 & 7 & & \\
\hline & 27 & 20 & 23 & 16 & 5 & 8 & 11 & 2 & & \\
\hline 25 & 22 & 15 & 18 & 13 & 51 & 3 & 6 & 9 & & \\
\hline 28 & 31 & 26 & 52 & & 56 & 10 & 54 & 75 & 72 & \\
\hline 35 & 38 & 33 & 30 & 50 & 53 & 58 & 73 & 78 & & 76 \\
\hline 32 & 29 & 36 & 47 & 57 & 49 & 55 & 60 & 71 & 74 & 79 \\
\hline 37 & 34 & 39 & 42 & 45 & 59 & 68 & 65 & 62 & 77 & \\
\hline 40 & 43 & 46 & & 48 & 64 & 61 & 70 & 67 & 80 & $\mathrm{~F}$ \\
\hline & & 41 & 44 & & 69 & 66 & 63 & & & \\
\hline
\end{tabular}


PUZZLE 5

Write the number you will try to reach in one minute.

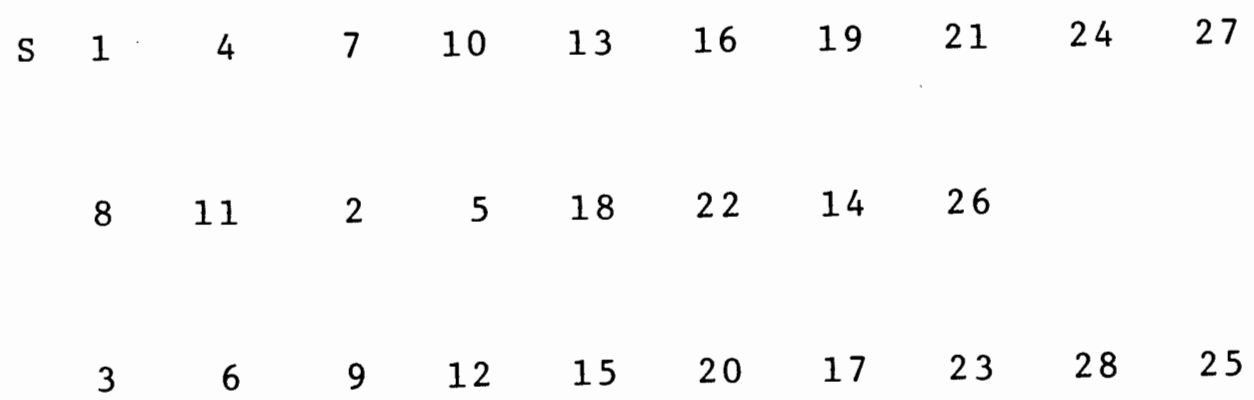

$\begin{array}{llllllllll}53 & 50 & 45 & 48 & 39 & 42 & 37 & 30 & 35 & 32\end{array}$

$\begin{array}{lllllll}47 & 54 & 51 & 44 & 40 & 33 & 29\end{array}$

$\begin{array}{llllllllll}55 & 52 & 49 & 46 & 41 & 38 & 43 & 36 & 31 & 34\end{array}$

$\begin{array}{lllllllll}59 & 56 & 65 & 62 & 67 & 70 & 73 & 76 & 79\end{array}$

$\begin{array}{lllllll}57 & 64 & 61 & 68 & 71 & 74 & 78\end{array}$

$\begin{array}{lllllllll}60 & 58 & 63 & 66 & 69 & 72 & 75 & 80 & 77\end{array}$ 
PARENTAL INFORMATION FORM

This form will remain strictly confidential.

Your name:

How much schooling have you completed? (Circle one):

$10-4$ years

2 5-8 years

3 some high school

4 graduated from high school
5 trade school or business school

6 some college (including junior college)

7 graduated from a 4-year college

8 post graduate work at a college or university

Child's name:

Age :

Sex :

Your relationship to the child (e.g., mother, father):

Child's birth order (Circle one):

1 first-born or only child 4 fourth born

2 second born

3 third born

5 fifth born

6 other:

Child's grade in school (Circle one): 4th 5th 6 th

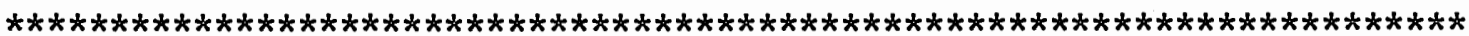

Many parents have some ideas about certain goals their child should achieve. For example, you might expect your child to do well in school. While some parents may communicate their goals to their children, others may not. In this study we are interested in goals you may have for your child.

Please answer the following questions as objectively as possible. Circle the number which best describes your position. Please do not place circles between numbers.

For example, if you expect you child to win in sports competitions most of the time, but not all of the time, you would circle the number " 6 " on the following scale:

How often do you expect your child to win in sports competitions?

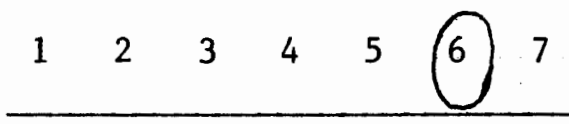

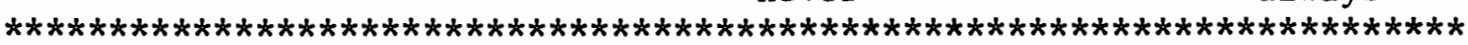

1. Do you set educational goals for your child?

$\begin{array}{lllllll}1 & 2 & 3 & 4 & 5 & 6 & 7\end{array}$


2. If you set goals for your child, how would you compare them to goals other parents set for their children?

3. Do you think goal-setting in general is valuable?

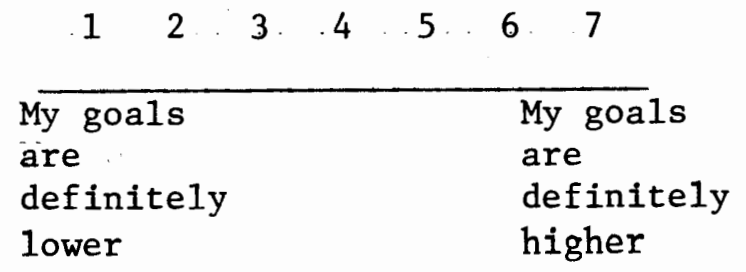

$\begin{array}{lllllll}1 & 2 & 3 & 4 & 5 & 6 & 7 \\ \begin{array}{l}\text { not at } \\ \text { all } \\ \text { valuable }\end{array} & & & & & \begin{array}{c}\text { very } \\ \text { valuable }\end{array} \\ & & & & \end{array}$

4. How would you rate your child's ability compared to other children of the same age?

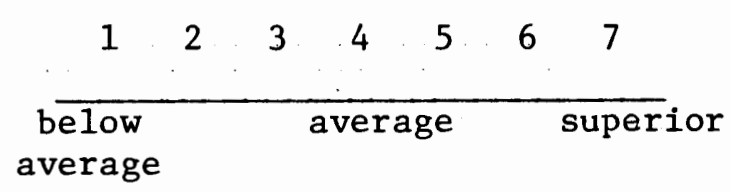

5. What is the highest educational level you want to see your child achieve?

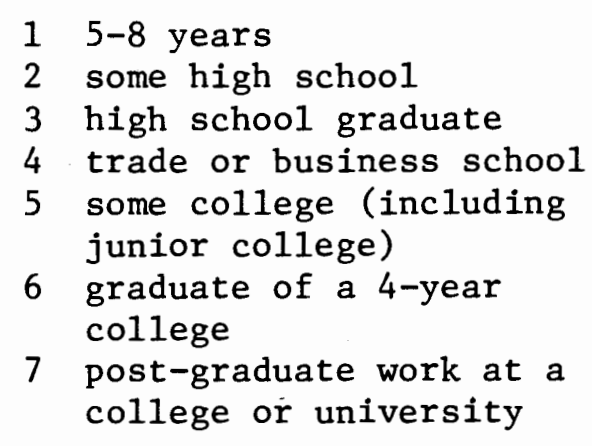

6. Does your child complain about the goals you set for him or her?

\begin{tabular}{|c|c|c|c|c|c|c|}
\hline 1 & 2 & 3 & 4 & 5 & 6 & 7 \\
\hline \multicolumn{5}{|l|}{ never } & \multicolumn{2}{|c|}{ always } \\
\hline 1 & 2 & 3 & 4 & 5 & 6 & 7 \\
\hline \multicolumn{5}{|l|}{ never } & \multicolumn{2}{|c|}{ always } \\
\hline 1 & 2 & 3 & 4 & 5 & 6 & 7 \\
\hline fini & & & & & & $\begin{array}{l}\text { early } \\
\text { ows }\end{array}$ \\
\hline
\end{tabular}

7. Does your child attain the goals you set for him or her?

8. Does your child know what you expect from him or her? 
9. Give some examples of educational goals you might set for your child.

10. Give some examples of other types of goals you might set for your child.

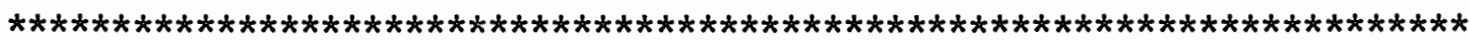

Please make sure you have answered each of the questions above. If you are not sure about an answer, try to make an "educated guess". Please do not leave any questions unanswered.

Thank you for your cooperation. Please return this form with the signed consent form in the enclosed envelope. 
APPENDIX D

EXPERIMENTAL INSTRUCTIONS 


\section{EXPERIMENTAL INSTRUCTIONS}

A booklet consisting of a cover sheet and the 5 puzzles was placed before each child. The children were asked not to open the booklets or mark on them until they were given permission to do so.

Investigator: What we are going to do today is complete 5 "Connect the Numbers" puzzles. Each puzzle begins with the number 1 and ends with the number 80 . For each puzzle your task is to draw a line connecting the numbers in order from the number 1 to the last number, just like the example on your booklet. As you can see in your example, the line connects the numbers in order from one, marked $S$ for START, to 2, then to 3 , then to 4 , and so on to 11 , the last number, marked $F$ for FINISH.

Now I want you to try the example on your paper. Draw an unbroken line from $S$ to $F$, connecting the numbers in order from 1 to 13. Good.

Now I want you to imagine for a while how long 1 minute is. Can you think of how long a minute is? In the next 5 puzzles I am going to give you 15 seconds to look over each puzzle, and 1 minute to work each puzzle. The last number of the puzzles in this booklet is 80 . You may not get that far in the 1 minute time period. This is $0 . K$. I just want you to try to connect as many numbers as you can in the 1 minute.

Before you begin each puzzle I want you to think of what number you will try to reach in the 1 minute: Before I tell you to start working the puzzle, I want you to write the number you will try to reach in the blank on the top of the page. Does everyone understand what we are going to do?

Now turn the page to Puzzle 1. You will now have 15 seconds to look over the puzzle. Do not begin connecting the numbers until I tell you to do so.

The children are now given 15 seconds to examine the puzzle.

Investigator: Now I want you to write the number that you will try to reach in the blank at the top of the page. Has everyone written the number they will try to reach? Good.

When I say "Go", begin connecting the numbers. Try to connect as many numbers as you can in 1 
minute. Ready. Go.

The children are now given 1 minute to work the puzzle.

Investigator: Stop. Very good. Now turn the page to puzzle 2. You will have 15 seconds to look over the puzzle. Do not begin connecting the numbers until I tell you to do so.

Instructions are repeated through the fifth puzzle. 
Once the Hunter-Wolf $A-B$ Rating Scale and the Puzzlès had been completed and collected, the children were debriefed. The experimenter informed the children that she was studying how children with different personality types performed on these puzzles. Children were also told that their parents would be given the results of the study once it was completed. The experimenter answered any questions the students had before proceeding to the next classroom. 